\title{
A Reversible Early Oxidized Redox State That Precedes Macromolecular ROS Damage in Aging Nontransgenic and 3xTg-AD Mouse Neurons
}

\author{
Debolina Ghosh, ${ }^{1}$ Kelsey R. LeVault, ${ }^{1}$ Aaron J. Barnett, ${ }^{1}$ and Gregory J. Brewer ${ }^{1,2}$ \\ Departments of ${ }^{1}$ Medical Microbiology, Immunology and Cell Biology and ${ }^{2}$ Neurology, Southern Illinois University School of Medicine, Springfield, Illinois \\ 62794-9626
}

\begin{abstract}
The brain depends on redox electrons from nicotinamide adenine dinucleotide (reduced form; NADH) to produce ATP and oxyradicals (reactive oxygen species [ROS]). Because ROS damage and mitochondrial dysregulation are prominent in aging and Alzheimer's disease (AD) and their relationship to the redox state is unclear, we wanted to know whether an oxidative redox shift precedes these markers and leads to macromolecular damage in a mouse model of $\mathrm{AD}$. We used the 3xTg-AD mouse model, which displays cognitive deficits beginning at 4 months. Hippocampal/cortical neurons were isolated across the age span and cultured in common nutrients to control for possible hormonal and vascular differences. We found an increase of $\mathrm{NAD}(\mathrm{P}) \mathrm{H}$ levels and redox state in nontransgenic (non-Tg) neurons until middle age, followed by a decline in old age. The 3xTg-AD neurons maintained much lower resting NAD(P)H and redox states after 4 months, but the NADH regenerating capacity continuously declined with age beginning at 2 months. These redox characteristics were partially reversible with nicotinamide, a biosynthetic precursor of $\mathrm{NAD}^{+}$. Nicotinamide also protected against glutamate excitotoxicity. Compared with non-Tg neurons, 3xTg-AD neurons had more mitochondria/neuron and lower glutathione (GSH) levels that preceded age-related increases in ROS levels. These GSH deficits were again reversible with nicotinamide in 3xTg-AD neurons. Surprisingly, low macromolecular ROS damage was only elevated after 4 months in the 3xTg-AD neurons if antioxidants were removed. The present data suggest that a more oxidized redox state and a lower antioxidant GSH defense can be dissociated from neuronal ROS damage, changes that precede the onset of cognitive deficits in the 3xTg-AD model.
\end{abstract}

\section{Introduction}

The brain depends on the redox reaction of nicotinamide adenine dinucleotide (reduced form; $\mathrm{NADH}$ ) to transfer electrons to oxygen in the production of ATP by oxidative phosphorylation. Some of the electrons escape tight controls to reduce oxygen to $\mathrm{O}_{2}^{-}, \mathrm{H}_{2} \mathrm{O}_{2}, \mathrm{OH}$, and $\mathrm{ONOO}^{-}$, collectively called reactive oxygen species (ROS), which can damage macromolecules. With aging and in Alzheimer's disease (AD), ROS damages brain proteins (Butterfield et al., 1998; Hensley et al., 1998; Smith et al., 1998), lipids (Montine et al., 1998), and nucleic acids (Nunomura et al., 1999), but determining whether these are a consequence of metabolic aging or are causal to $\mathrm{AD}$ has been elusive. The major electron transfer currencies for oxidation and reduction reactions in cells are the redox couples NADH/NAD ${ }^{+}$and NADPH/

\footnotetext{
Received Dec. 13, 2011; revised Feb. 20, 2012; accepted March 14, 2012.

Author contributions: D.G. and G.J.B. designed research; D.G., K.R.L., and A.J.B. performed research; D.G., K.R.L., and A.J.B. analyzed data; D.G., K.R.L., A.J.B., and G.J.B. wrote the paper.

This work was supported by National Institutes of Health Grants R01 AG032431 and AG13435, and by the Stark Endowed Chair for Alzheimer's Research. We thank Salvatore Oddo and Frank LaFerla for contributing the founder mice used in this study.

The authors declare no competing financial interests.

Correspondence should be addressed to Gregory J. Brewer, Department of Medical Microbiology, Immunology and Cell Biology, Southern Illinois University School of Medicine, Springfield, IL 62794-9626. E-mail: Gbrewer@siumed.edu.

DOI:10.1523/JNEUROSCI.6192-11.2012

Copyright $\odot 2012$ the authors $\quad 0270-6474 / 12 / 325821-12 \$ 15.00 / 0$
}

$\mathrm{NADP}^{+}$. A reductive shift in redox is associated with cell proliferation, an oxidative shift with morbidity and apoptosis (Jones, 2006). These principles led us to formulate the epigenetic oxidized redox shift (EORS) theory of aging (Brewer, 2010) and propose that an oxidized redox state is upstream of ROS generation. Here, we test the hypothesis that an age-related oxidized redox shift is upstream of elevated ROS levels and reported cognitive deficits. We determine the redox shift as intrinsic fluorescence of intracellular NADH (Chance and Williams, 1956; Chance et al., 1979) in isolated neurons with reference to the oxidized flavin nucleotide FAD (Parihar et al., 2008). Given that $0.1 \mathrm{~mm} \mathrm{NADH}$ is the major intracellular redox currency with eight times more free energy than ATP (Klaidman et al., 1995; Brewer, 2010) and millimolar glutathione (GSH) (Kudo et al., 1990 ) is the major redox buffer in cells (Das and White, 2002), we further hypothesized that aging is associated with an oxidized redox state evident as an oxidative shift in the $\mathrm{NAD}(\mathrm{P}) \mathrm{H} / \mathrm{FAD}$ redox ratio and a decline in GSH levels that precede elevations in ROS.

Nicotinamide, a biosynthetic precursor of $\mathrm{NAD}^{+}$, was previously shown to increase NADH and NADPH levels in striatum and thalamus of whole-brain tissue of adult mouse (Klaidman et al., 2001). However, the AD- and age-dependent effects of nicotinamide on neurons remain unclear. Nicotinamide also improved the cognitive deficits, which begin at 4 months, in a hippocampus- and amygdala-dependent task in a triple trans- 
genic mouse model of AD (3xTg-AD) (Oddo et al., 2003a,b) by selectively decreasing Thr231 phospho-tau, increasing stabilizing acetylated $\alpha$-tubulin, and increasing synaptogenic p25, all associated with improved learning and memory (Green et al., 2008). These findings led us to investigate whether nicotinamide could increase intracellular $\mathrm{NAD}(\mathrm{P}) \mathrm{H}$ levels and change the redox state in 3xTg-AD mice. We measured other possible events upstream of AD-like pathology, including cytochrome $c$ release, GSH antioxidant defenses, and macromolecular damage in aging and in a male 3xTg-AD mouse model to determine the relationship between ROS damage and the onset of cognitive changes in these mice. We used cultured adult neurons (Brewer, 1997; Brewer and Torricelli, 2007) that enable age-related comparisons of neurons under common culture conditions that control or eliminate hormonal, vascular, and inflammatory changes present during aging in vivo.

\section{Materials and Methods}

Mouse model. We used LaFerla's triple transgenic mouse model of AD (3xTg-AD) with human transgenes APP (SWE), PS1 (M146V), and Tau (P301L) under the control of Thy1.2 promoters (Oddo et al., 2003b). Nontransgenic (non-Tg) mice on the same mixed C57BL/6/129 background as the $3 \mathrm{xTg}-\mathrm{AD}$ mice were used as controls. For all our experiments, we used male $3 \mathrm{xTg}$-AD and non-Tg animals that were housed one to four per cage, fed rodent diet 5001 (LabDiet; Purina, with 28.5\% calories from protein, $13.5 \%$ from fat, and $58 \%$ from carbohydrates) ad libitum at controlled temperature and humidity and a $12 \mathrm{~h} \mathrm{light/dark}$ cycle. All animals underwent genotyping before experiments. DNA was extracted from tail snips using Roche High Pure PCR Template Preparation Kit. We used two primer sets for identifying the 3xTg-AD mutant. The following primers identified the PS1 gene: forward, 5'-CAC ACG CAA CTC TGA CAT GCA CAG GC-3'; reverse, 5' -AGG CAG GAA GAT CAC GTG TTC AAG TAC-3' (Invitrogen). The PCR product was digested with the restriction enzyme BstEII (New England BioLabs). Non-Tg mice showed a single band $(\sim 550 \mathrm{bp})$, and 3xTg-AD mice showed two bands ( $\sim 300$ and $250 \mathrm{bp}$ ). The following primers identified the $h A P P$ gene: forward, $5^{\prime}$-GCT TGC ACC AGT TCT GGA TGG-3'; reverse, $5^{\prime}$-GAG GTA TTC AGT CAT GTG CT-3'. Non-Tg mice showed no amplification, and 3xTg-AD mice showed one band ( $\sim 300 \mathrm{bp})$.

Primary neuron culture. Adult hippocampal and cortical neurons were isolated from non- $\mathrm{Tg}$ and $3 \mathrm{xTg}-\mathrm{AD}$ age-matched male mice at 2-, 4-, 8-, 11-, and 21-month time points (Brewer and Torricelli, 2007). The combined hippocampus and frontal cortex of each hemisphere $(\sim 140 \mathrm{mg}$ of tissue) were sliced at $0.5 \mathrm{~mm}$ and combined in Hibernate A (BrainBits), 2\% B27 supplement (Invitrogen), and 0.5 mm Glutamax (Invitrogen). The tissue was digested with $2 \mathrm{mg} / \mathrm{ml}$ papain (Worthington) for $30 \mathrm{~min}$ at $30^{\circ} \mathrm{C}$. Slices were triturated, and the neurons were separated from debris and microglia on an Optiprep (Sigma-Aldrich) density gradient. To limit the toxicity caused by excess debris, each hippocampus and hemicortex was digested, triturated, and spun through a density gradient in separate tubes. After the gradient, the neuron-enriched fractions of each hippocampus and frontal cortex were combined. Viable cells were counted by exclusion of trypan blue. Neurons were plated at 32,000 cells $/ \mathrm{cm}^{2}$ on 12 and $15 \mathrm{~mm}$ glass coverslips (Assistant; Carolina Biological) that were coated overnight with poly-D-lysine, $100 \mu \mathrm{g} / \mathrm{ml}$ in water. The cells were plated and cultured in Neurobasal A/B27/Glutamax (Invitrogen) with $10 \mathrm{ng} / \mathrm{ml} \mathrm{FGF2}$ and $10 \mathrm{ng} / \mathrm{ml} \mathrm{PGDFbb}$ (Invitrogen) for trophic support. Cells were cultured for $7-12 \mathrm{~d}$ at $37^{\circ} \mathrm{C}$ in $5 \% \mathrm{CO}_{2}, 9 \% \mathrm{O}_{2}$ at saturated humidity (Forma).

Live-dead assay. For neuron survival, live cells on glass coverslips were stained with fluorescein diacetate ( $15 \mu \mathrm{g} / \mathrm{ml}$; Sigma-Aldrich), and dead cells were stained with propidium iodide $(4.6 \mu \mathrm{g} / \mathrm{ml}$; Sigma-Aldrich) (Brewer et al., 1993). After the slips were washed with HBSS (Invitrogen), cells were observed by blue and green fluorescence excitation through a $20 \times$ objective (Olympus) for green and red fluorescence. Survival was calculated as the average percentage of live cells divided by the total cells (live plus dead) in 8-12 adjacent fields.
$N A D(P) H$ and FAD measurements from intrinsic fluorescence. Single live cells were imaged for simultaneous $\mathrm{NAD}(\mathrm{P}) \mathrm{H}$ and FAD measurements as described previously (Parihar et al., 2008) with slight modification. Because our system cannot distinguish between NADH and $\mathrm{NAD}(\mathrm{P}) \mathrm{H}$ fluorescence, we use the more general term NADPH for our experiments. However, $80 \%$ of autofluorescence originates from NADH (Eng et al., 1989), so we can assume that NADH contributes maximally to the $\mathrm{NAD}(\mathrm{P}) \mathrm{H}$ autofluorescence pool. Cells cultured for $8 \mathrm{~d}$ on $15 \mathrm{~mm}$ glass coverslips were mounted on a slip holder (Warner Instruments) in $500 \mu \mathrm{l}$ of Hibernate A Low Fluorescence (BrainBits) and $0.5 \mathrm{~mm}$ Glutamax. Hibernate A clamps the $\mathrm{pH}$ at 7.3 and contains the same amino acids, salts, and vitamins as the culture medium. Twenty micrometer polystyrene beads (Polysciences) were added to approximate the neuron diameter and to create a fixed space between two coverslips to reduce evaporation and provide a constant optical thickness; they also served as a focusing aid. Three hundred fifty nanometers of light were used to excite NADH using a $75 \mathrm{~W}$ Xenon arc lamp [Deltaram V (slits open two turns each); Photon Technology International] attached to a dual Photometer D104 controlled by Felix GX software (Photon Technology International) and observed under a Nikon $40 \times$ oil objective. The dichroic used for simultaneously exciting NADH and FAD was a 450 dcxru (Nikon) in a Nikon Diaphot 300 microscope with a beam splitter having a $490 \mathrm{~nm}$ DCLP dichroic with $460 \mathrm{~nm}$ bandpass emitter filter (S460/36; Chroma) for NADH and a $490 \mathrm{~nm}$ long-pass filter for FAD. Because emission spectra for NADH and NADPH overlap, we use the general term $\mathrm{NAD}(\mathrm{P}) \mathrm{H}$ to indicate that fluorescence was generated from either or both nucleotides. The photomultiplier voltage for $\mathrm{NAD}(\mathrm{P}) \mathrm{H}$ was set at $1000 \mathrm{~V}$, and for FAD it was set at $850 \mathrm{~V}$. Each cell was isolated with a constant $20 \mu \mathrm{m}$ square slit and measured for $1 \mathrm{~s}$ every $6 \mathrm{~s}$ over $60 \mathrm{~s}$. Five to six cells were imaged in a programmed order with the help of an automated stage (Ludl Electronic Products). To convert fluorescent intensities (counts/second) to micromolar concentrations, the system response was calibrated to a concentration curve $(0-200 \mu \mathrm{M})$ of NAD(P)H and FAD (Parihar et al., 2008). Background fluorescence was subtracted before results were analyzed for $\mathrm{NAD}(\mathrm{P}) \mathrm{H}, \mathrm{FAD}$ concentration, and redox ratio $(\mathrm{NAD}(\mathrm{P}) \mathrm{H} / \mathrm{FAD})$.

To measure NADH regenerating capacity, we determined the difference between NADH in neurons with $5 \mu \mathrm{m}$ rotenone to block consumption at complex I (maximum) from NADH after treatment with $1 \mu \mathrm{M}$ oligomycin to block ATP synthase activity, followed by $1 \mu \mathrm{M}$ carbonyl cyanide $p$-trifluoromethoxyphenylhydrazone (FCCP) to uncouple the respiratory chain to drive maximum $\mathrm{NADH}$ consumption (minimum $\mathrm{NADH})$.

Nicotinamide treatment. Nicotinamide (Sigma) was prepared in Neurobasal A, $0.5 \mathrm{~mm}$ Glutamax. Neurons were treated for $15-16 \mathrm{~h}$ with or without nicotinamide.

HPLC of adenine nucleotides. Extraction, derivatization, and analysis of brain NAD/NADH was adapted from Klaidman et al. (1995). Anesthetized animals were decapitated into liquid nitrogen to rapidly quench all metabolism. Approximately $40 \mathrm{mg}$ of combined hippocampus and cortex was dissected in Hibernate A (BrainBits) at $4^{\circ} \mathrm{C}$. The tissue was weighed and homogenized in $5 \mu \mathrm{l} / \mathrm{mg} 0.2 \mathrm{M} \mathrm{KCN}, 0.06 \mathrm{M} \mathrm{KOH}, 1 \mathrm{~mm}$ bathophenanthroline disulfonic acid (BPDS) (catalog \#146617; Sigma) with a plastic pestle (K749520 -0000; Fisher Scientific) on ice and reacted for 5 min to produce stable cyanide derivatives of the adenine nucleotides. The derivatized homogenate was extracted with chloroform and centrifuged at $17,000 \times g$ for $5 \mathrm{~min}$ at $4^{\circ} \mathrm{C}$. The upper layer was again extracted with chloroform and centrifuged. The aqueous portion was then filtered through a $0.45 \mu \mathrm{m}$ nylon filter (CoStar Spin-X; Corning) by centrifuging at $14,000 \times g$ for $10 \mathrm{~min}$ at $4^{\circ} \mathrm{C}$. The filter tube was then rinsed with $30 \mu \mathrm{l}$ of $0.2 \mathrm{M} \mathrm{KCN}, 0.06 \mathrm{M} \mathrm{KOH}$, and $1 \mathrm{~mm}$ BPDS, and was spun for an additional $5 \mathrm{~min}$ to recover residual sample. Samples were stored at $-70^{\circ} \mathrm{C}$ until analysis. Before injection onto the column, samples were diluted with one-sixteenth part $1.6 \mathrm{~m}$ ammonium acetate, $\mathrm{pH}$ 6.0 ( $8 \times$ mobile phase). An injection volume of $20 \mu \mathrm{l}$ was applied to a $250 \times 4.6 \mathrm{~mm}, 5 \mu \mathrm{m}$ ProteCol GP C18 125 reverse-phase column (SGE Analytical Science). Analytes were detected by fluorescence (excitation, $330 \mathrm{~nm}$; emission, $460 \mathrm{~nm}$ ) on a Waters Breeze 2 HPLC System. The mobile phase consisted of two solutions. Solvent A was $0.2 \mathrm{M}$ ammonium 
acetate (Fisher Scientific), pH 6.0. Solvent B was 50\% $0.2 \mathrm{M}$ ammonium acetate, pH 6.0 and 50\% HPLC grade methanol. A gradient of mobile phase began as $92 \%$ solvent A, $8 \%$ solvent B. After 1 min, solvent B was increased at a rate of $0.4 \%$ for $25 \mathrm{~min}$. The flow rate was $1 \mathrm{ml} / \mathrm{min}$. Freshly made $1.5 \mathrm{~mm}$ standards of NAD and NADH were diluted to 5-30 $\mu \mathrm{m}$ with $0.2 \mathrm{M} \mathrm{KCN}, 0.06 \mathrm{M} \mathrm{KOH}$, and $1 \mathrm{~mm}$ BPDS, and were reacted for $5 \mathrm{~min}$. Derivatized standards were diluted with one-sixteenth part $1.6 \mathrm{M}$ ammonium acetate, $\mathrm{pH}$ 6.0. We used the Nernst equation to calculate the redox state of the tissue, $E h=E_{0}-2.3(R T / n F) \log ([\mathrm{NADH}] /[\mathrm{NAD}])$, with the standard potential relative to hydrogen, $E_{0}=-370 \mathrm{mV}$, the gas constant $R=1.987 \mathrm{cal} /($ degree $\times \mathrm{mol}), T=310^{\circ} \mathrm{K}, n=1$ electron transfer, and the Faraday constant $F=23.062 \mathrm{cal} /(\mathrm{mol} \times \mathrm{mV})$.

Simultaneous measurement of ROS and glutathione in live cells. To determine ROS levels and antioxidant GSH defenses, we followed the protocol used before (Brewer et al., 2010) with few changes. At $8 \mathrm{~d}$ in culture, $100 \%$ of the media containing antioxidants in the B27 was replaced with Neurobasal A/Glutamax without B27 for $15 \mathrm{~h}$ at $37^{\circ} \mathrm{C}, 5 \% \mathrm{CO}_{2}$, and $9 \%$ $\mathrm{O}_{2}$. Before experiments, cells attached to $15 \mathrm{~mm}$ glass coverslips were mounted in a slip holder in $800 \mu \mathrm{l}$ of Neurobasal A, Glutamax, and $20 \mu \mathrm{M}$ $2^{\prime}, 7^{\prime}$-dichlorofluorescein (DCF) diacetate (Invitrogen) for $20 \mathrm{~min}$. During the last $5 \mathrm{~min}$ of DCF incubation, $100 \mu \mathrm{M}$ monochlorobimane (MCB, M1381; Invitrogen) was added to measure GSH (Hulbert and Yakubu, 1983). After incubation, cells were rinsed twice with Hibernate A low fluorescence, Glutamax containing $4.6 \mu \mathrm{g} / \mathrm{ml}$ propidium iodide (PI) to stain any dead cells. Dead cells were not included in the analysis because of their high ROS and low GSH signal. Cells were imaged through a $40 \times$ objective/numerical aperture 0.60 using Olympus optics: 4,6-diamidino2-phenylindole-2-HCl (DAPI filter for MCB), fluorescein isothiocyanate (FITC filter for DCF), and tetramethylrhodamine isothiocyanate (TRITC filter for PI). Image-Pro Plus software (version 7.0; Media Cybernetics) was used for analysis of fluorescence intensity.

Fura-2 calcium imaging in live neurons. Live adult neurons were imaged for intracellular calcium as described previously (Brewer et al., 2006). Briefly, neurons were loaded with $5 \mu \mathrm{M}$ Fura-2-AM (Invitrogen) for $45 \mathrm{~min}$ in Krebs' buffer ( $100 \mathrm{~mm} \mathrm{NaCl}, 20 \mathrm{~mm} \mathrm{KCl}, 1 \mathrm{mM} \mathrm{MgCl}_{2}, 1 \mathrm{~mm}$ $\mathrm{CaCl}_{2}, 1 \mathrm{~mm} \mathrm{NaH} \mathrm{PO}_{4}, 4.2 \mathrm{~mm} \mathrm{NaHCO}, 10 \mathrm{~mm}$ glucose, $12.5 \mathrm{~mm}$ MOPS, pH 7.3) in 5\% $\mathrm{CO}_{2}, 9 \% \mathrm{O}_{2}$, followed by de-esterification for 30 min in Krebs' buffer. Twenty to 30 neurons were imaged using Easy Ratio Pro software (Photon Technology International) and a CoolSnap HQ 25 (Photometrics) charge-coupled device camera. Fluorescence was excited alternately between 340 and $380 \mathrm{~nm}$ for $400 \mathrm{~ms}$ using a Fura-2/rhodamine filter (Chroma) and a Nikon $40 \times$ oil objective.

Immunostaining of macromolecular damage in fixed cells. Neurons cultured for $8 \mathrm{~d}$ attached to $15 \mathrm{~mm}$ glass coverslips were fixed with $4 \%$ paraformaldehyde in PBS (minus magnesium and calcium) for $10 \mathrm{~min}$. Then a blocking and permeabilization solution of $1 \%$ Triton X-100, 1\% bovine serum albumin (BSA) in PBS was applied to the slips for $10 \mathrm{~min}$. Primary antibodies, rabbit anti-OH-nonenal IgG (ALX-210-767; Enzo Life Sciences), and mouse anti-8-OH-guanosine (QED Biosciences) were diluted with $0.02 \%$ Triton X-100, 1\% BSA, in PBS 1:500 and 1:82.5, respectively. The primary antibodies were allowed to bind overnight at $4^{\circ} \mathrm{C}$. Secondary antibodies Alexa Fluor 488 goat anti-rabbit (Invitrogen) diluted 1:300 and Alexa Fluor 568 goat anti-mouse (Invitrogen) diluted 1:2000 were allowed to bind for $1 \mathrm{~h}$ at room temperature. Bisbenzamide, final concentration $0.33 \mu \mathrm{g} / \mathrm{ml}$, was applied to slips for $2 \mathrm{~min}$ to label nuclei. Neurons used as a positive control were treated with $20 \mu \mathrm{m}$ hydrogen peroxide $\left(\mathrm{H}_{2} \mathrm{O}_{2}\right)$ for $10 \mathrm{~min}$. Coverslips were mounted on a slide and imaged at $60 \times$ with an oil-immersion objective using Olympus dichroic filters for DAPI (bisbenzamide), FITC (OH-nonenal), and TRITC (OH-guanosine). Image-Pro Plus software was used for analysis of fluorescence intensity with constant thresholds for each age and genotype. For experiments without antioxidants, neurons were cultured with B27 without antioxidants (Invitrogen). Total fluorescence per cell was calculated as fluorescence intensity $X$ area of cell $\left(\mu \mathrm{m}^{2}\right) / 1000$.

Cytochrome c measurements. Neurons were rinsed with PBS and fixed with $4 \%$ paraformaldehyde in PBS (minus magnesium and calcium). After blocking with 3\% BSA, 0.05\% saponin in PBS, cytochrome $c$ levels were detected using sheep anti-rabbit cytochrome $c$ (Sigma; diluted 1:200) and Alexa Fluor 488 donkey anti-rabbit antibodies (Invitrogen;
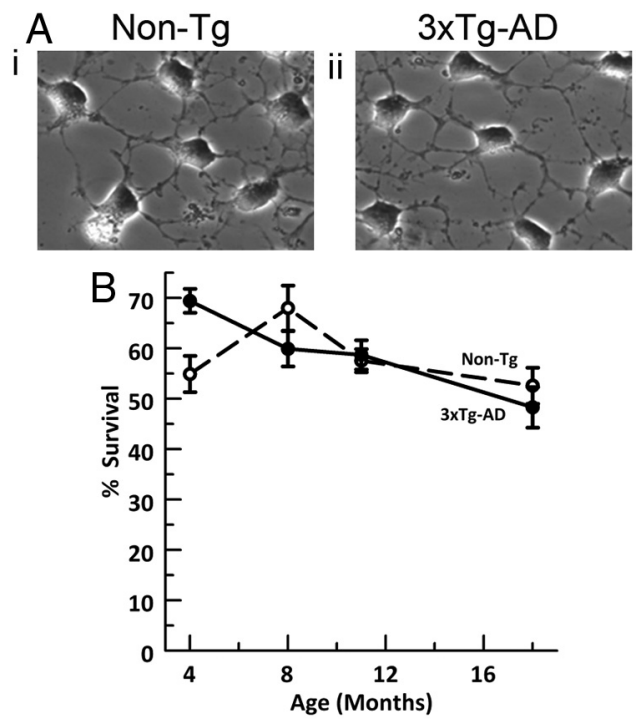

Figure 1. Similar neuron culture and viability with age and genotype. $A$, Two-month-old cultured neurons of non- $\mathrm{Tg}(\boldsymbol{A} \boldsymbol{i})$ and $3 \times \mathrm{Tg}-\mathrm{AD}(\boldsymbol{A i i})$, grown for 9 days in vitro under the same conditions. $\boldsymbol{B}$, Survival percentages of cultured neurons over age: Non-Tg (open circles); $3 x \operatorname{Tg}-\mathrm{AD}$ (closed circles). $N=2-3$ mice per genotype.

diluted 1:2000). Images were acquired at $100 \times$ and analyzed using Image Pro Plus software. Images were segmented into bright and dim objects. The bright-intensity objects measured cytochrome $c$ concentrated in mitochondria, while the dim-intensity objects measured the cytoplasmic cytochrome $c$.

Statistics. Data are presented as means and SEs. Student's $t$ test was used to assess the difference of means using Prostat (Poly Software). We used $p<0.05$ to reject the null hypothesis.

\section{Results}

\section{No age-related loss of viability of neurons in culture}

To evaluate neuron function with age, independent of an aging hormonal, immune, and vascular system, we isolated neurons from the frontal cortex and hippocampus of mice across their age span. Figure 1 shows that non-Tg (Fig. $1 A$ ) and 3xTg-AD (Fig. $1 B$ ) neurons in uniform culture medium have similar healthy morphology. There is also no difference between viability in non-Tg and 3xTg-AD neuronal cultures over the entire age span of the mouse. Neuronal viability does not decrease with age in uniform cultures (Fig. 1C).

\section{Determination of $\mathrm{NAD}(\mathrm{P}) \mathrm{H}$ concentrations and redox state with age and in $3 \times \mathrm{Tg}-\mathrm{AD}$ mouse neurons}

Given that brain deficit in the primary electron donor (NADH) to the electron transport chain would severely limit the capacity to generate ATP, we examined the $\mathrm{NAD}(\mathrm{P}) \mathrm{H}$ levels in isolated neurons as a function of age or AD-like genotype. Because autofluorescence of $\mathrm{NADH}$ cannot be distinguished from $\mathrm{NAD}(\mathrm{P}) \mathrm{H}$ in our system, we used the term $\mathrm{NAD}(\mathrm{P}) \mathrm{H}$ for our measurements. To determine the $\mathrm{NAD}(\mathrm{P}) \mathrm{H}$ concentration of non-Tg and $3 \mathrm{xTg}-\mathrm{AD}$ cultured neurons, intrinsic fluorescence of $\mathrm{NAD}(\mathrm{P}) \mathrm{H}$ was measured microscopically from individual neurons with detection by split-beam photomultipliers to simultaneously measure the reduced $\mathrm{NAD}(\mathrm{P}) \mathrm{H}$ and the oxidized FAD. Figure $2 A$ shows the $\mathrm{NAD}(\mathrm{P}) \mathrm{H}$ concentration in live neurons from both non-Tg and 3xTg-AD mice at different ages, starting from sexual maturity at 2 months, through middle age at 11 months, and into old age at 21 months, near the median life span. In non-Tg mouse neurons (Fig. $2 A$ ), the $\mathrm{NAD}(\mathrm{P}) \mathrm{H}$ started at a low concentration $(60 \mu \mathrm{M})$ that rose 


\section{A $\mathrm{NAD}(\mathrm{P}) \mathrm{H}$ concentration}

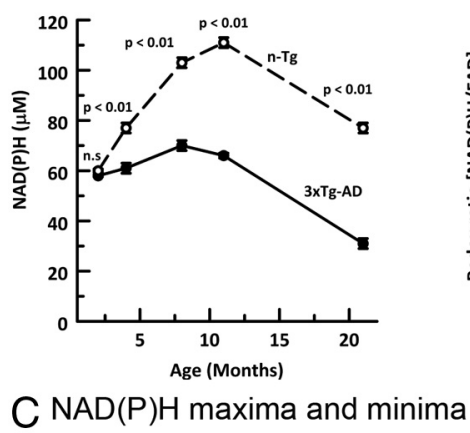

B Redox ratio [NAD(P)H/FAD]
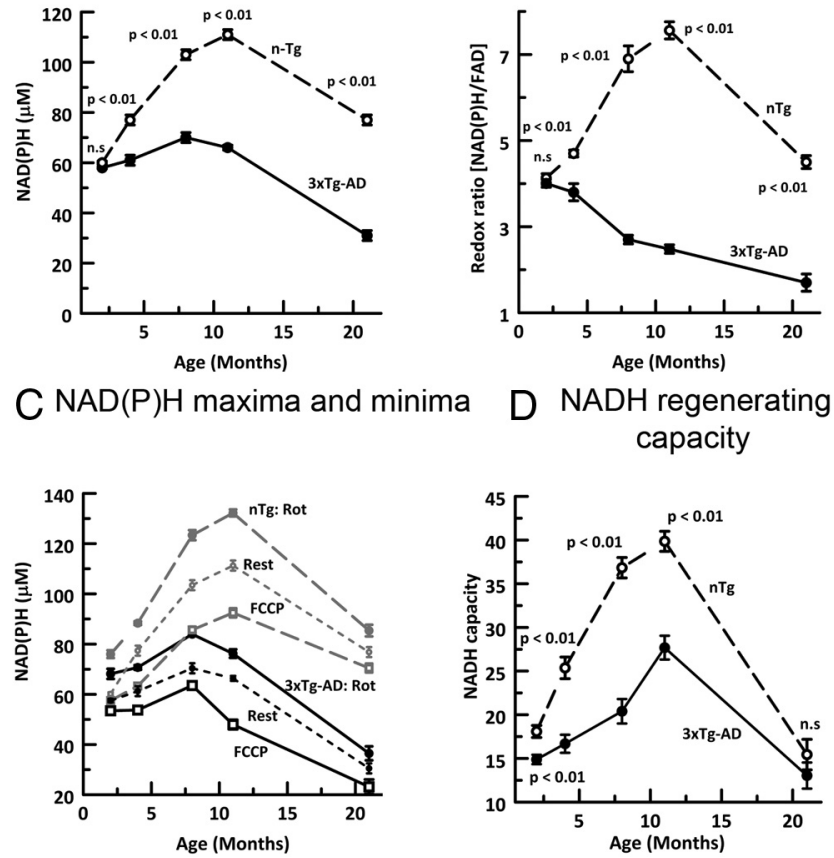

Figure 2. Age and genotype of neurons affects $N A D(P) H$ concentration, redox ratio, and $\mathrm{NADH}$ regenerating capacity. $A, \mathrm{NAD}(\mathrm{P}) \mathrm{H}$ concentration $(\mu \mathrm{M})$ in non- $\mathrm{Tg}$ (open circles) is higher than that in $3 \times T$ Tg-AD (closed circles) at indicated ages after 2 months. $\boldsymbol{B}$, Redox ratio [NAD(P)H/ FAD] of non- Tg is higher than that in 3xTg-AD after 2 months. C, Maxima and minima NAD(P)H concentration $(\mu \mathrm{M})$ in non- $\mathrm{Tg}$ (gray lines) are higher than those of $3 \times \mathrm{Tg}-\mathrm{AD}$ neurons beginning at 2 months (black lines). Minimal NAD(P)H level was initiated by adding FCCP, and maximal $\mathrm{NAD}(\mathrm{P}) \mathrm{H}$ levels were found by adding rotenone. The maxima and minima $\mathrm{NAD}(\mathrm{P}) \mathrm{H}$ were compared with the resting NAD(P)H. D, NADH regenerating capacity shows a genotype difference beginning at 2 months. The regenerating capacity was obtained from the difference of maxima and minima NADH of both genotypes with non-Tg and $3 \times \mathrm{Tg}-\mathrm{AD}$. The different time points for all the experiments for both genotypes are 2, 4, 8, 11, and 21 months. $N=10-12$ neurons from two mice per genotype.

$85 \%$ with development to $111 \mu \mathrm{M}$ at 11 months (middle age), after which the $\mathrm{NAD}(\mathrm{P}) \mathrm{H}$ concentration dropped $33 \%$ to $77 \mu \mathrm{M}$ in old age. Although 3xTg-AD mouse neurons started at the same $\mathrm{NAD}(\mathrm{P}) \mathrm{H}$ concentration as non- $\mathrm{Tg}$ mouse neurons $(58 \mu \mathrm{M})$, $\mathrm{NAD}(\mathrm{P}) \mathrm{H}$ concentration increased toward middle age by only $21 \%$, then began to decline earlier after 8 months by $56 \%$ to 30 $\mu \mathrm{M}$ in old age. The final $\mathrm{NAD}(\mathrm{P}) \mathrm{H}$ concentration in $3 \times \mathrm{Tg}-\mathrm{AD}$ neurons was only $39 \%$ that of non-Tg neurons.

The ratio of the reduced $[\mathrm{NAD}(\mathrm{P}) \mathrm{H}]$ divided by the oxidized [FAD] is a useful proxy for the redox state of the cell, more precisely indicated by the ratio of the $[\mathrm{NADH}] /\left[\mathrm{NAD}^{+}\right]$(Chance and Williams, 1956; Chance et al., 1979). The use of the FAD measure is necessitated by the nonfluorescent properties of $\mathrm{NAD}^{+}$, while FAD and $\mathrm{NAD}(\mathrm{P}) \mathrm{H}$ exhibit intrinsic fluorescence microscopically measurable in single cells. Figure $2 B$ shows the ratio of reduced $[\mathrm{NAD}(\mathrm{P}) \mathrm{H}] /$ oxidized $[\mathrm{FAD}]$ (redox ratio) in neurons of both genotypes across the age span. In non- $\mathrm{Tg}$ neurons, the redox ratio mimics the $\mathrm{NAD}(\mathrm{P}) \mathrm{H}$ profile with a shift toward a reduced redox peak at middle age and an oxidized shift in old age. In contrast to non-Tg neurons, the redox ratio in the $3 \mathrm{xTg}-\mathrm{AD}$ neurons declined continuously with age toward a $62 \%$ more oxidized redox state. These results suggest that the redox state of live single neurons varies with age and genotype in large, reproducible ways, with potential impact on numerous metabolic functions.

\section{NADH regenerating capacity}

Because aging and the $3 \mathrm{xTg}-\mathrm{AD}$ genotype caused a lower $\mathrm{NAD}(\mathrm{P}) \mathrm{H}$ concentration and a more oxidized redox state, we wanted to investigate whether this lower $\mathrm{NAD}(\mathrm{P}) \mathrm{H}$ in $3 \mathrm{xTg}-\mathrm{AD}$ neurons resulted from higher NADH consumption by complex I of the electron transport chain or from lower NADH regenerating capacity by lactate and pyruvate dehydrogenases and Krebs' cycle dehydrogenases compared with non-Tg neurons. Either way, the imbalance would produce a more oxidized redox state insufficient to withstand a challenge of oxidative stress. We compared NADH levels under two conditions. First, to minimize NADH levels and maximize consumption, we added oligomycin to block the reversal of ATPase and FCCP to dissipate the proton gradient and to maximally consume NADH by stimulation of complex I (NADH dehydrogenase), the major consumer of NADH for electron transport down the chain to oxygen. Second, we blocked complex I with $5 \mu \mathrm{M}$ rotenone to minimize NADH consumption and maximize NADH levels. At 2 months for both genotypes, the resting NADH levels were near those with FCCP added, indicating that the youngest neurons were operating near their maximum capacity to consume NADH. At all subsequent ages, the resting levels of $\mathrm{NADH}$ were near the midpoint between uncoupled FCCP levels and consumption-inhibited rotenone levels (Fig. 2C).

The difference between the maximum and minimum NADH concentrations evoked by rotenone and FCCP provides a measure of the NADH regenerating capacity. Figure $2 D$ shows that both genotypes showed an increase in NADH regenerating capacity until middle age, after which they dramatically declined to similarly low levels in old age. Compared with non-Tg neurons, $3 x T g-A D$ neurons showed significant deficits in NADH regenerating capacity from the earliest age of 2 months. However, this early deficit was amplified at 4,8 , and 11 months, suggesting that $\mathrm{NADH}$ regenerating capacity is further impaired with age. Because FCCP lowers NADH levels and rotenone raises NADH levels in all ages and both genotypes, complex I use is not impaired in either the $3 \mathrm{xTg}-\mathrm{AD}$ or the non-Tg neurons.

\section{Reversal of $\mathrm{NAD}(\mathrm{P}) \mathrm{H}$ and redox deficits with nicotinamide}

Nicotinamide, a precursor of $\mathrm{NAD}^{+}$(Ying, 2008), reverses learning deficits in the $3 \times \mathrm{XTg}-\mathrm{AD}$ mouse (Green et al., 2008) with a mechanism attributed to epigenetic changes based on acetylation of phospho-tau Thr231. Here, we consider an alternative mechanism in which nicotinamide is first an $\mathrm{NAD}^{+}$and then an $\mathrm{NADH}$ precursor to supply more energy to neurons. Treatment of 21-month-old neurons with increasing doses of nicotinamide for $15 \mathrm{~h}$ produced an inverted $\mathrm{U}$-response in neuron $\mathrm{NAD}(\mathrm{P}) \mathrm{H}$ levels and redox ratios (Fig. $3 A, B$ ). Two millimolar nicotinamide produced a maximum response. In 21-month-old non- $\mathrm{Tg}$ neurons, nicotinamide raised the $[\mathrm{NAD}(\mathrm{P}) \mathrm{H}]$ from 76 to $95 \mu \mathrm{M}$ and produced a reductive shift in the redox ratio from 4.3 to 5.4, increasing both concentration and redox ratio by $25 \%$ (Fig. $3 A, B)$. Nicotinamide treatment of 21-month-old 3xTg-AD neurons led to an increase in $[\mathrm{NAD}(\mathrm{P}) \mathrm{H}]$ from 30 to $54 \mu \mathrm{M}$ and in the redox ratio from 1.8 to 2.5 , leading to larger increases of $80 \%$ in $\mathrm{NAD}(\mathrm{P}) \mathrm{H}$ and $39 \%$ in the redox ratio, respectively, but it failed to restore these neurons to levels present in non-Tg neurons. Treatment of 11-month-old neurons with $2 \mathrm{~mm}$ nicotinamide produced non-Tg shifts from 110 to $129 \mu \mathrm{M} \mathrm{NAD}(\mathrm{P}) \mathrm{H}$ and 3xTg-AD shifts from 68 to $109 \mu \mathrm{M}$ NAD(P)H. Treatment of 2-month-old neurons with $2 \mathrm{~mm}$ nicotinamide produced non-Tg shifts from 61 to $86 \mu \mathrm{M} \mathrm{NAD}(\mathrm{P}) \mathrm{H}$ and $3 \mathrm{xTg}-\mathrm{AD}$ shifts from 58 to $80 \mu \mathrm{M}$ $\mathrm{NAD}(\mathrm{P}) \mathrm{H}$. 
A $\mathrm{NAD}(\mathrm{P}) \mathrm{H}$ concentration

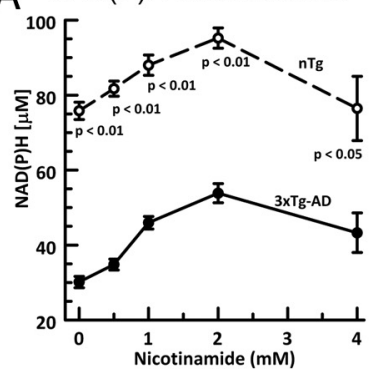

B Redox ratio $[N A D(P) H / F A D]$

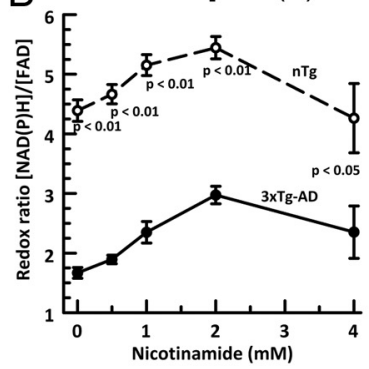

C NADH regenerating capacity

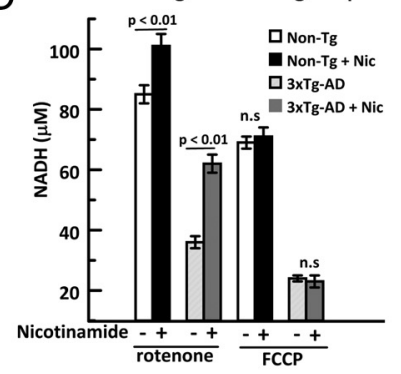

$\mathrm{D}$

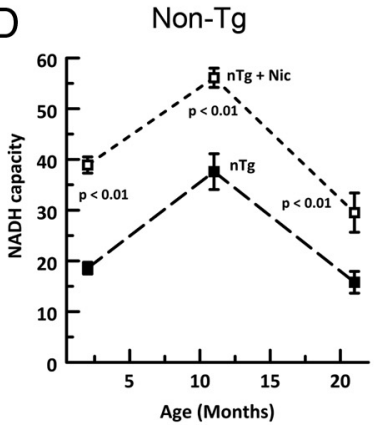

E

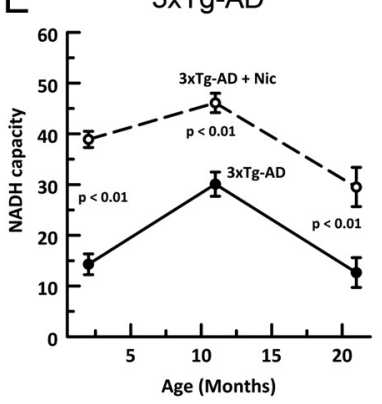

Figure 3. Nicotinamide (Nic) increases neuronal NAD(P)H, redox ratio, and regenerating capacity across the age span. Nicotinamide dose response in neurons of 21-month-old non- $\mathrm{Tg}$ (open circles) and $3 \times \mathrm{Tg}-\mathrm{AD}$ (closed circles) animals. $\boldsymbol{A}, \mathrm{NAD}(\mathrm{P}) \mathrm{H}$ concentration. $\boldsymbol{B}$, $N A D(P) H / F A D$ redox ratio. $C$, Nicotinamide increases NADH regenerating capacity in 21month-old non- $\mathrm{Tg}$ and $3 \mathrm{xTg}-\mathrm{AD}$ neurons in the presence of rotenone, while the response to FCCP remains unaffected. $\boldsymbol{D}, \boldsymbol{E}$, Nicotinamide increases NADH capacity of non- $\mathrm{Tg}(\boldsymbol{D})$ and $3 x \operatorname{Tg}-\mathrm{AD}(\boldsymbol{E})$ neurons across the age span. $N=10-12$ neurons from two mice per genotype.

To determine the effect of nicotinamide on regenerating capacity, we treated cells with FCCP and rotenone as before. We observed that in 21-month-old animals of both genotypes, nicotinamide treatment increased the maximal NADH (rotenone added) but had no effect on the minimal NADH levels (FCCP added) (Fig. 3C). Similarly, treatment of 2- and 11month-old neurons of either genotype with nicotinamide did not change the minimum NADH levels generated by FCCP (data not shown), suggesting complex I was not impaired in the $3 \mathrm{xTg}-\mathrm{AD}$ neurons. However, as in Figure $3 \mathrm{C}$ for 21 month-old neurons and for 2- and 11-month-old neurons (data not shown), the maximum levels of NADH in the presence of rotenone were increased. The net results in Figure 3, $D$ and $E$, show the effect of $2 \mathrm{~mm}$ nicotinamide on the NADH regenerating capacity. At 2, 11, and 21 months, treatment with nicotinamide increased the regenerating capacity similarly for both $3 \times \mathrm{Tg}-\mathrm{AD}$ and non-Tg neurons. These results suggest that $\mathrm{NADH}$ regenerating capacity is impaired in $3 \mathrm{xTg}$-AD neurons but can be fully restored to non-Tg levels by $15 \mathrm{~h}$ treatment with nicotinamide at either 2 or 21 months.
Simultaneous changes in ROS levels and glutathione production in live neurons

Increased ROS levels is one of the major copathologies in aging and AD (Carney et al., 1994; Emerit et al., 2004). Because an $\mathrm{NAD}(\mathrm{P}) \mathrm{H}$ oxidized redox state in $3 \mathrm{xTg}-\mathrm{AD}$ neurons and in old non- $\operatorname{Tg}$ neurons also decreases its antioxidant ability, we wanted to determine the relationship between impaired $\mathrm{NAD}(\mathrm{P}) \mathrm{H}$ levels and ROS levels across the age span as well as simultaneous measures of the antioxidant buffer GSH. The oxidized redox state could result from increased ROS levels and/or decreased GSH defenses. We used fluorescent probes dichlorofluorescein diacetate (fluorescent product DCF) to detect ROS levels (Parihar and Brewer, 2007) and MCB to label GSH production (Hulbert and Yakubu, 1983). Although DCF does not react directly with singlet oxygen, it can react with several reactive species such as $\mathrm{OH}$, $\mathrm{NO}_{2}^{-}$, and peroxynitrites (Kalyanaraman et al., 2012) and can damage macromolecules. ROS and GSH levels from live non- $\mathrm{Tg}$ and $3 \mathrm{xTg}-\mathrm{AD}$ neurons from 8-month-old brains are shown in Figure 4, $A$ and $B$. Qualitatively, non-Tg neurons (Fig. 4A) show stronger intensity of GSH label than 3xTg-AD neurons (Fig. $4 B$ ), with a merge as light blue neurons. The reverse was observed for ROS with non-Tg neuron levels low (Fig. 4A) and higher intensity levels in 3xTg-AD neurons (Fig. $4 B$ ), with the merged image showing the stronger ROS green stain.

Compared quantitatively, the ROS levels of 3xTg-AD and non- $\mathrm{Tg}$ neurons began at low and equal levels at 2 and 4 months of age (Fig. 4C). However, after 4 months, ROS levels increase sharply for both genotypes, with a significantly faster increase with age for 3xTg-AD than non-Tg neurons. The old-age level of ROS levels for non-Tg neurons was already attained at 8 months in the 3xTg-AD neurons. In the same cells, we simultaneously determined the levels of GSH as the primary cellular antioxidant buffer. We hypothesized that increased ROS would be buffered by increased GSH but that, in old age, either production of GSH would decline or more GSH would be consumed by even higher ROS. Further, we predicted that the $3 \mathrm{xTg}-\mathrm{AD}$ neurons, with their increased energy demands from birth because of higher resting calcium levels, would reach this critical point of insufficient ROS buffering at an earlier age. Figure $4 D$ shows a significant deficit in GSH levels in 3xTg-AD neurons relative to non-Tg neurons starting at 2 months of age. Although both genotypes increased their GSH levels as ROS increased through middle age, the increase for $3 \times \mathrm{Tg}$-AD neurons was significantly lower. Both genotypes produced lower levels of GSH from middle to old age, reaching levels below those at the start of life. Compared with non-Tg neurons, GSH levels in 3xTg-AD neurons remained significantly lower at all ages.

These simultaneous measures allow comparisons of the relative aging kinetics of increases in ROS and declines in GSH buffering of ROS. Focusing first on non-Tg neurons, Figure $4 E$ shows that GSH levels generally increase at the same rate as ROS levels until middle age. In old age, GSH levels decline much faster, creating an arbitrary crossover point at 17 months. In 3xTg-AD neurons, a similar crossover point occurs at only 7 months of age (Fig. 4F). The larger rise in ROS in the 3xTg-AD neurons from 4 to 11 months, compared with non-Tg neurons, may contribute to the failure of GSH to rise over this period. The further rise in ROS from 11 to 21 months in both genotypes, which correlates with a greater decline in GSH over this period, highlights the need for further studies regarding a threshold level of ROS, above which GSH is catastrophically consumed. This experiment suggests that 3xTg-AD deficits in GSH occur before excess ROS in 

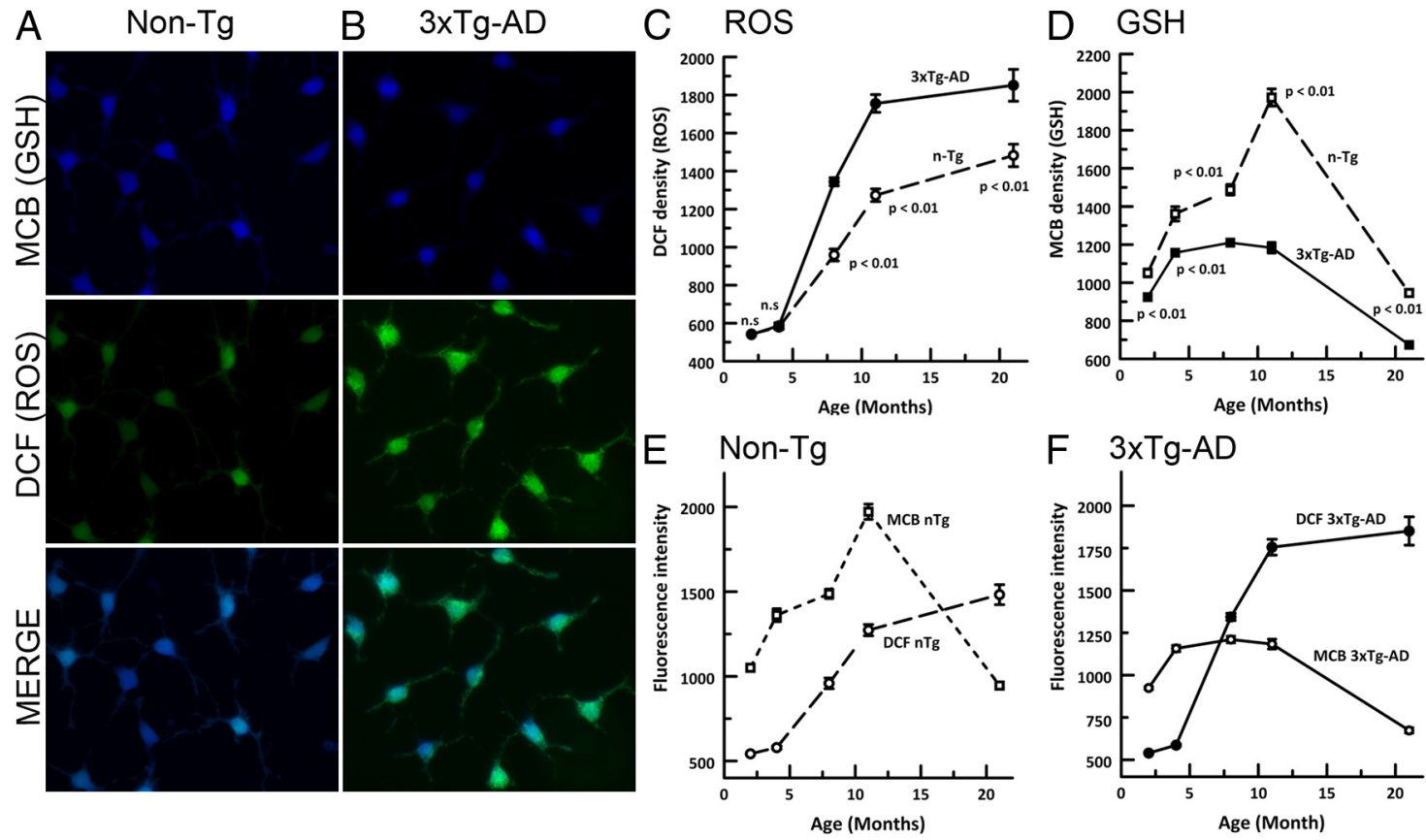

Figure 4. Delayed ROS levels and early GSH deficits in neurons. $A, B$, Simultaneous measurement of GSH with MCB and ROS with DCF and their merged effect on live 8-month-old cultured non-Tg neurons $(\boldsymbol{A})$ and live 8-month-old 3xTg-AD neurons ( $\boldsymbol{B})$. C, ROS fluorescence intensity from DCF density at the indicated ages of non-(open circles) Tg and 3xTg-AD (closed circles). $\boldsymbol{D}$, GSH fluorescence intensity from MCB density of non- $\operatorname{Tg}$ (open circles) and 3xTg-AD (closed circles). $\boldsymbol{E}$, To better compare the effect of age for each genotype, in non-Tg neurons, ROS and GSH levels increase in parallel until middle age, after which GSH levels decline. F, In 3xTg-AD neurons, ROS levels increase to a greater extent than they do in non-Tg neurons, and GSH production plateaus at an early age, 4 months, before declining after middle age. $N=3-4$ mice per genotype and age.

3xTg-AD neurons that become more acute as ROS levels increase and GSH buffers are consumed into middle age and old age.

\section{Nicotinamide increased glutathione levels and decreased ROS levels in 3xTg-AD neurons}

Because nicotinamide partially reversed the oxidative redox shift toward a reduced redox state and increased NAD $(\mathrm{P}) \mathrm{H}$ concentration, we hypothesized that nicotinamide treatment would lower ROS levels by first increasing GSH regeneration from its oxidized form (GSSG) through NADPH-dependent GSH reductase followed by GSH reduction of $\mathrm{H}_{2} \mathrm{O}_{2}$ by GSH peroxidase and other reactions. The first reaction may not be detectable by measuring GSH regeneration if a cell is at a steady-state equilibrium of GSH/GSSG. To test our hypothesis, we chose the 8 month time point because GSH levels in 3xTg-AD neurons declined after 8 months. Figure $5 \mathrm{~A}$ shows that pretreatment with nicotinamide for non-Tg neurons did not alter GSH levels, whereas in $3 x T g-A D$ neurons nicotinamide increased GSH levels by $30 \%$. Simultaneous measures of ROS levels (Fig. $5 B$ ) revealed that non-Tg neurons did not alter their ROS levels in response to nicotinamide; treated 3xTg-AD neurons showed a 20\% decrease in the ROS level. However, despite this significant decrease in ROS levels in 3xTg-AD neurons, the overall ROS levels remained significantly higher than in non-Tg neurons. One possible explanation for why ROS is not restored to the same levels as in non- $\mathrm{Tg}$ neurons is that other ROS sources remain unaffected by nicotinamide-enhanced $\mathrm{NAD}(\mathrm{P}) \mathrm{H}$. In addition, the unaltered GSH levels in non-Tg neurons treated with nicotinamide suggest that non-Tg neurons are already regenerating enough GSH from GSSG to maintain a normal redox state.

\section{Nicotinamide rescued cells from glutamate-induced excitotoxicity}

Because glutamate excitotoxicity is implicated in aging and $\mathrm{AD}$, we wanted to determine further whether nicotinamide can rescue neurons from glutamate-induced excitotoxicity. We chose our middle-aged (11-month) and old (21-month) animals to compare neuron viability. Figure 6 shows percentages dead in 11month-old (Fig. 6A) and 21-month-old (Fig. 6B) neurons of both genotypes with $100 \mu \mathrm{M}$ glutamate and $2 \mathrm{~mm}$ nicotinamide treatment. Compared with untreated neurons, glutamate treatment induced a twofold increase in death in both non-Tg and $3 \mathrm{xTg}-\mathrm{AD}$ neurons. However, cotreatment with nicotinamide and glutamate largely protected neurons from glutamate excitotoxicity ( $p<0.001$ for 11 months; $p<0.02$ for 21 months). Although nicotinamide reduced glutamate toxicity in non- $\mathrm{Tg}$ neurons to the level in untreated neurons, the treatment reduced by only $50 \%$ the toxicity in 21 -month-old $3 x T$-AD neurons. This increased susceptibility of $3 \times \mathrm{Tg}-\mathrm{AD}$ neurons to glutamate toxicity suggests that factors other than $\mathrm{NAD}(\mathrm{P}) \mathrm{H}$ and $\mathrm{GSH}$ are involved in $\mathrm{AD}$-like toxicity because these neuroprotectants appear to be fully restored by nicotinamide.

\section{Calcium dysregulation in adult 3xTg-AD neurons}

3xTg-AD neurons have threefold to fivefold higher intracellular calcium concentrations (Smith et al., 2005a; Stutzmann et al., 2006) at birth than non-Tg neurons. To confirm calcium dysregulation in adult neurons, we performed intracellular calcium imaging of 11-month-old non-Tg and 3xTg-AD neurons. We found that while the $[\mathrm{Ca}]_{\mathrm{i}}$ in non-Tg neurons was $109 \mathrm{nM}$, $3 x T g-A D$ neurons had more than twofold higher $[\mathrm{Ca}]_{\mathrm{i}}$ at $253 \mathrm{~nm}$ (data not shown), which confirmed the previous study in primary neurons, cultured from 8 - to 12 -month-old 3xTg-AD mice (Lopez et al., 2008).

Mitochondrial and cytoplasmic cytochrome $c$ levels increase with age and $\mathrm{AD}$ genotype

Mitochondrial function is impaired in both aging and AD. However, it remains unanswered whether mitochondrial dysfunction 

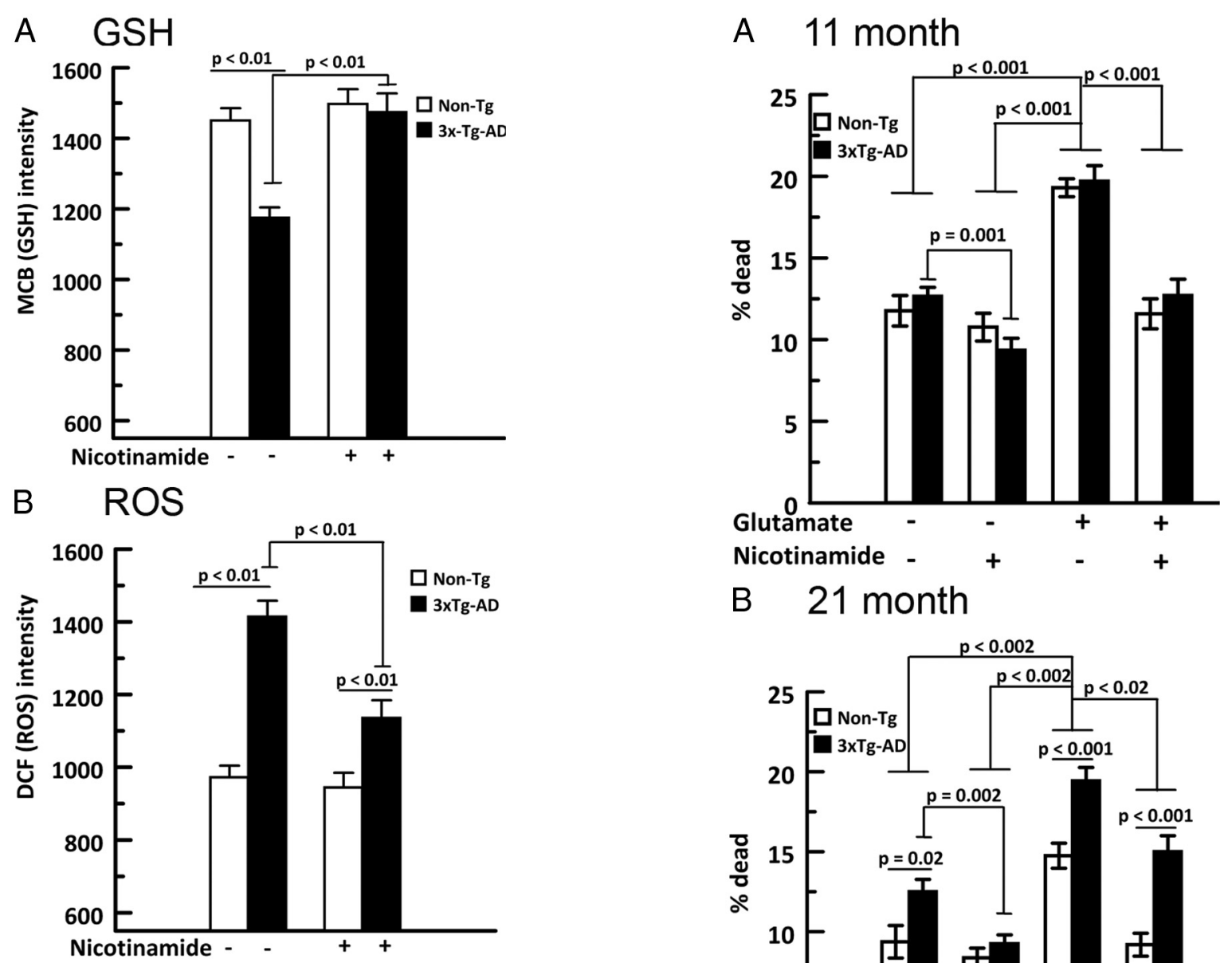

B 21 month

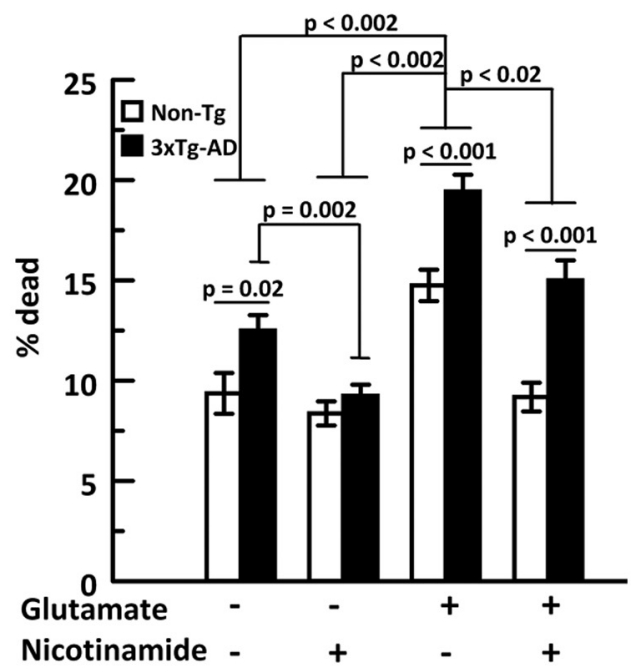

causes the rise in ROS and oxidative shift in redox or whether ROS causes the mitochondrial dysfunction and oxidative shift. One line of evidence for causation is precedence: if event A precedes event B, then B cannot cause A. In our model system, to hypothesize that mitochondrial dysfunction causes a redox shift, early changes in mitochondrial function such as NADH regenerating capacity would precede redox changes and/or ROS. Given that healthy mitochondria retain and stressed mitochondria release cytochrome $c$, we determined the effect of age and genotype on neuronal and mitochondrial health.

According to hypothesis A, the increased genotypic stress on mitochondria causes increased release of cytochrome $c$ from mitochondria into the cytoplasm with age. Examination of the mean cytoplasmic cytochrome $c$ in Figure $7 A$ shows low levels at 2 months followed by increased cytoplasmic levels in non-Tg and even higher levels in 3xTg-AD neurons at middle age that remained high at old age. This increase in cytoplasmic cytochrome $c$ could lead to apoptosome activation. Hypothesis B was that $3 x T g-A D$ neurons have fewer healthy mitochondria because they are poisoned by the excess $\beta$-amyloid and calcium so that those remaining have to work harder. A corollary is that harder working mitochondria produce more ROS and/or consume more NADH. In contradiction to this hypothesis, Figure $7 B$ shows a higher mitochondrial count per cell in $3 \mathrm{xTg}-\mathrm{AD}$ neurons than in non-Tg neurons in early and middle age. These results suggest

Figure 6. Neuroprotection from glutamate excitotoxicity by nicotinamide. $A, B$, Elevenmonth-old $(\boldsymbol{A})$ and 21-month-old $(\boldsymbol{B})$ live non- $\mathrm{Tg}$ (white bars) and 3xTg-AD (black solid bars) neurons showing the percentages of dead neurons without (-) and with (+) $100 \mu \mathrm{m}$ glutamate only, $2 \mathrm{mM}$ nicotinamide only, or both. $N>200$ neurons from two mice per genotype per age and condition.

that the $3 \mathrm{xTg}-\mathrm{AD}$ neurons compensate for the increased genotypic stress by upregulating mitochondria in each cell. Higher measures of mitochondria per cell in 3xTg-AD compared with non-Tg neurons supports a compensatory bioenergetic mechanism in 3xTg-AD neurons. This higher mitochondrial count per cell in 3xTg-AD neurons is closely paralleled in Figure $7 C$ by a higher early and middle-age intensity of bright-level cytochrome $c$ immunoreactivity in the $3 \times \mathrm{Tg}$-AD neurons than in the non- $\mathrm{Tg}$ neurons, likely associated with mitochondria.

Macromolecular damage in neurons with age

If ROS levels increase with age or genotype beyond the detoxification ability of the cell, then nucleic acid and lipid macromolecular damage will occur (Reed et al., 2009). To assess ROS-induced macromolecular damage in these cultured neurons as a function of mouse age and genotype, Figure $8 \mathrm{~A}$ shows 11-month-old neurons double stained for oxidative damage to DNA and RNA using anti-8-OH-(deoxy)guanosine and for lipid peroxidation using 
A Cytosol

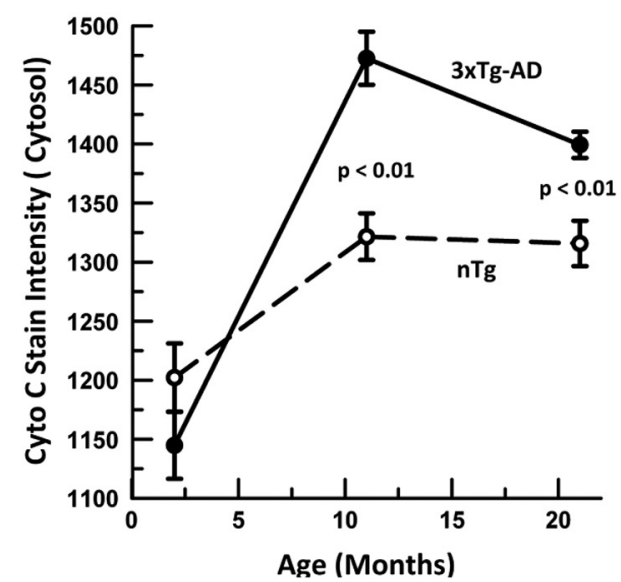

B Count

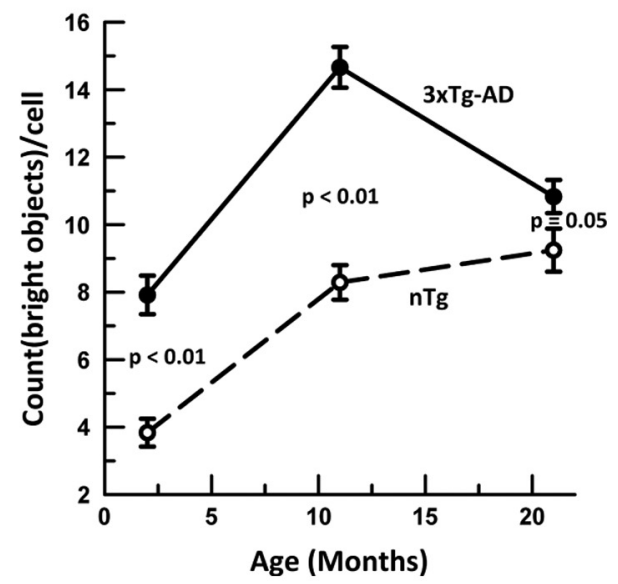

C Mitochondria

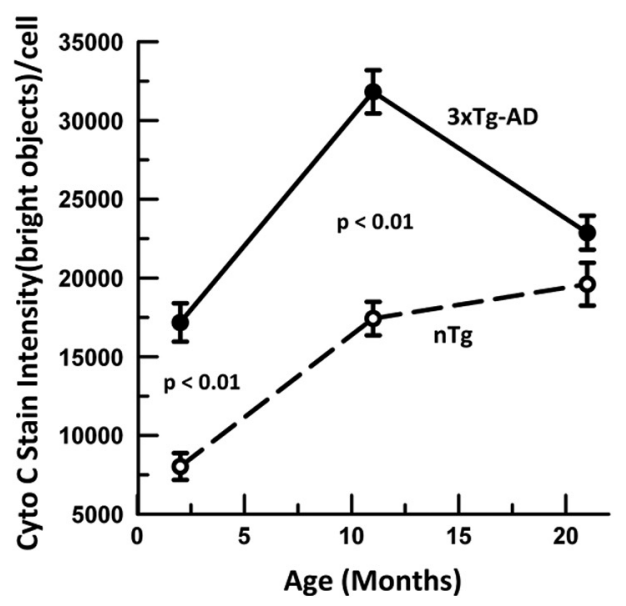

Figure 7. Cytoplasmic and mitochondrial distributions of cytochrome c (Cyto) immunoreactivity are both higher in $3 \times \mathrm{Tg}-\mathrm{AD}$ than in non-Tg neurons. $A$, Cytoplasmic levels of cytochrome $C$ increase from early ( 2 months) to middle age (11 months) but are higher in 3xTg-AD neurons at middle age and older age. $\boldsymbol{B}$, The numbers of bright intracellular objects (individual and clusters of mitochondria) are elevated at all ages in 3xTg-AD compared with non-Tg neurons and increase from early to middle age. $C$, The intensity of these bright objects follows a similar pattern of higher levels in the 3xTg-AD than in the non-Tg neurons at early age and middle age: $3 \times \mathrm{XTg}-\mathrm{AD}$ (filled circles); $N$ on- $\mathrm{Tg}$ (open circles). $N>60$ neurons for two mice at 2 months. $N>89$ neurons for three mice at 11 and 21 months for each genotype. anti-4-hydroxynonenal in the same neurons. To demonstrate the reliability of these probes and cellular responses, we also treated 4-month-old neurons with $20 \mu \mathrm{M} \mathrm{H}_{2} \mathrm{O}_{2}$ for $10 \mathrm{~min}$ to induce excess oxidative damage to the cells (positive control). Probes for both nucleic acid damage and lipid peroxidation dramatically increased after the $\mathrm{H}_{2} \mathrm{O}_{2}$ treatment. Despite an increase in ROS and oxidized redox state shown in Figures $4 C$ and $2 B$, we see in Figure $8, B$ and $C$, no indication of ROS-induced macromolecular damage in cultured neurons with age or genotype. This suggests that the antioxidants in the cells and in the culture medium were sufficient to protect against significant ROS damage to macromolecules. As an additional control, we removed the superoxide dismutase (SOD), catalase, GSH, vitamin E acetate, and vitamin $\mathrm{E}$ from the culture medium. This external manipulation was sufficient to elicit both nucleic acid and lipid damage to $3 \mathrm{xTg}-\mathrm{AD}$ neurons above those of non-Tg neurons from 4-month-old brains, whereas the 2-month-old neurons did not show any genotypic difference even with antioxidant removal (Fig. $8 E$ ).

\section{$\mathrm{NADH}$ concentration and redox ratio in whole brain}

To observe the redox state of brain tissue in vivo, which includes neurons with the support of other surrounding cell types, we analyzed hippocampal and cortical brain lysates by HPLC. Figure $9 A$ shows a $22 \%$ decrease in $\mathrm{NADH}$ concentration in the 2 -month-old $3 \times \mathrm{Tg}-\mathrm{AD}$ brain. The redox state of the $3 \mathrm{xTg}-\mathrm{AD}$ brain of 2-month-old animals (Fig. 9B) was significantly more oxidized $(-372 \mathrm{mV})$ than that of the non-Tg brain $(-387 \mathrm{mV})$. These results indicate that the redox state in the whole $3 \times \mathrm{Tg}-\mathrm{AD}$ brain reflects an oxidative shift seen in the cultured neuron model.

\section{Discussion}

The ability of neurons of old animals to regenerate in culture and their lack of abundant ROS damage argue against the theory that aging results from an irreversible lifelong buildup of ROS damage. Nevertheless, neurons from old non-Tg and 3xTg-AD mice showed deficits in NAD $(\mathrm{P}) \mathrm{H}$ levels, lower capacity to generate NAD $(\mathrm{P}) \mathrm{H}$, lower GSH levels, late elevated ROS, and failure to increase mitochondria to meet these energy demands. These aging effects indicate an early oxidized redox shift before ROS damage to macromolecules. Further, because of the rapid reversibility by nicotinamide of the oxidized redox shift and glutamate toxicity in neurons from old animals, we argue that processes associated with aging cause an important metabolic shift in reductive supply of energy as NADH to the electron transport chain. We (Brewer, 2010) and others (Anderson and Weindruch, 2010; Martin et al., 2010; Safdar et al., 2010) have hypothesized that a sedentary lifestyle causes this metabolic shift.

Regarding the $\mathrm{AD}$ model, we demonstrated that the redox ratio in the 3xTg-AD neurons never increased beyond 2-month levels and that $\mathrm{NAD}(\mathrm{P}) \mathrm{H}$ levels never increased above those of 4-month-old non-Tg neurons. Therefore, we predicted that restoration of $\mathrm{NAD}(\mathrm{P}) \mathrm{H}$ levels would reverse the low energetic capacity. Given that these genotype deficits could be reversed in $<24$ h with the $\mathrm{NAD}^{+}$precursor nicotinamide, we argue that the age-related shift in redox state is a critical target that the AD-like transgenes exacerbate beyond normal aging. Further, the $3 \times \mathrm{Tg}-\mathrm{AD}$ model shows impairment in GSH regeneration from 2 months on, never reaching levels of middle-age non-Tg neurons. Therefore, the supply of the key metabolites NADH and GSH 


\section{A Non-Tg}

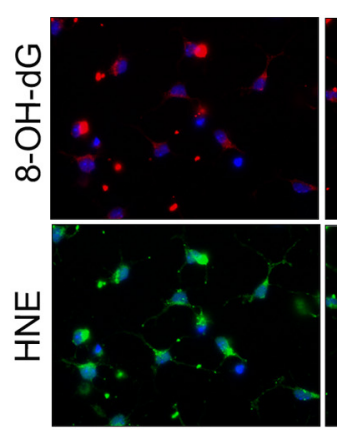

3xTg-AD
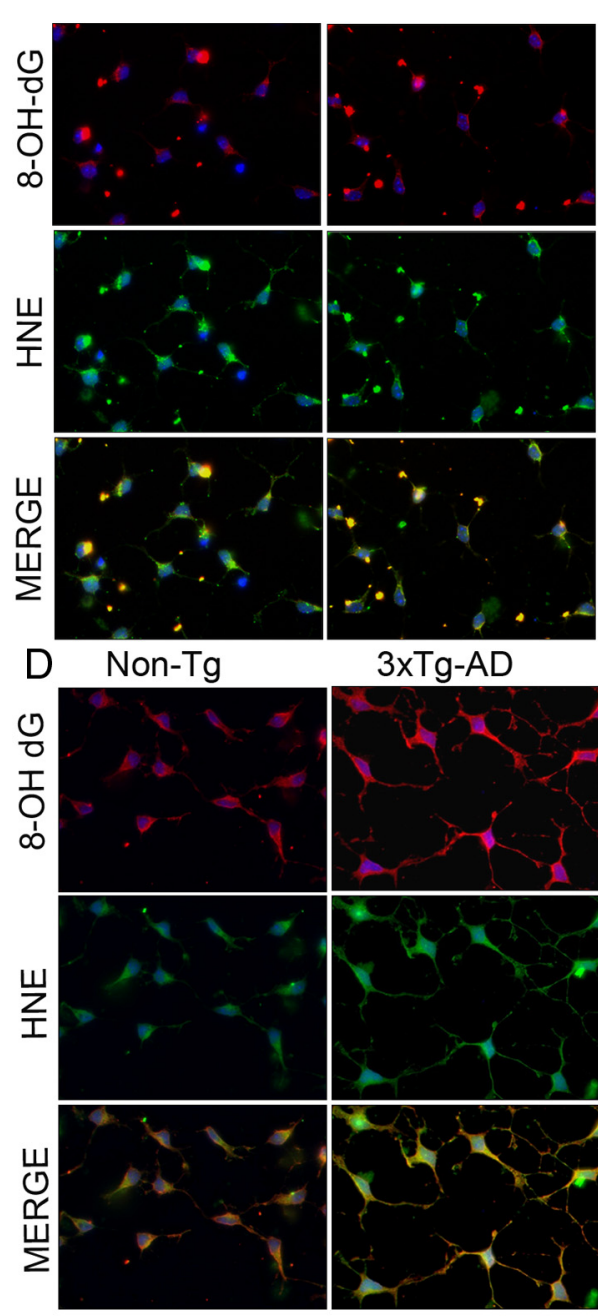

$3 \times T g-A D$

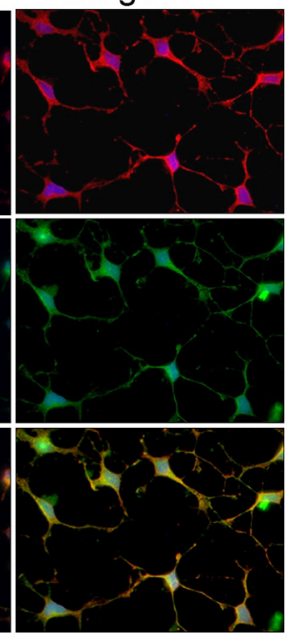

B $8-\mathrm{OH}-\mathrm{dG}$

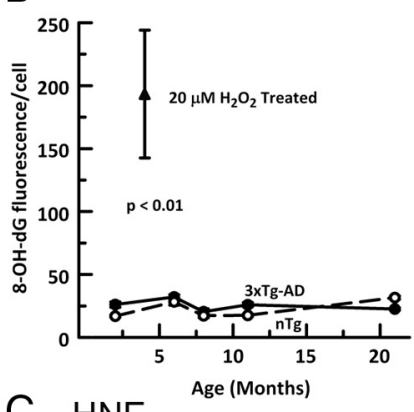

C HNE
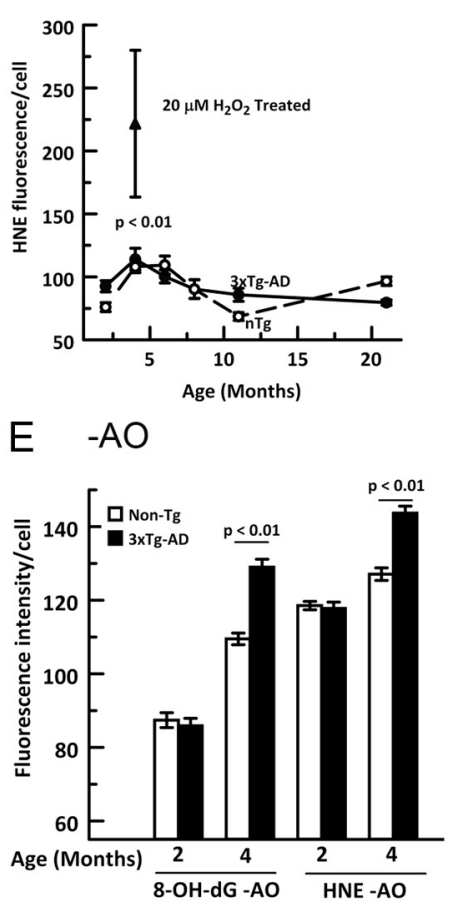

Figure 8. Absence of ROS-induced macromolecular damage in neurons in the presence of antioxidants and only elevated after 4 months in the $3 x T g-A D$ neurons if antioxidants were removed. $A$, Eleven-month-old non- $T g$ and $3 x T g$-AD neurons cultured in B27 (with antioxidants) were fixed with paraformaldehyde and probed for 8-hydroxy-(deoxy)guanosine (8-0H dG) (top) and 4-hydroxynonenal (HNE) (middle); merged image (bottom). B, C, No significant differences in macromolecular damage were seen with age or genotype. A positive control treated with $20 \mu \mathrm{M} \mathrm{H}_{2} \mathrm{O}_{2}$ (closed triangle) indicates sensitivity of the measures to high levels of oxidation. $\boldsymbol{D}$, In B27 without antioxidants, 4-month-old non- $\mathrm{Tg}$ and 3xTg-AD neurons indicated an increase in 8-OH dG (top) for both genotypes, but for HNE (middle), only the $3 x T g-A D$ neurons increased immunoreactivity; merged image (bottom). $\boldsymbol{E}$, Without antioxidants $(-\mathrm{A} 0)$, macromolecular damage was unchanged with genotype at 2 months but was higher at 4 months in $3 x T g-A D$ (closed bars) than in non-Tg neurons (open bars) for both 8-OH dG (left) and HNE (right). $N>200$ neurons from two to four mice per condition.

may restore sufficient reducing energy and antioxidant capacities to counter the impact of increased transgene expression.

These results support the novel proposition that an oxidative redox shift precedes increased ROS damage, cell damage, and cognitive decline with age, and in a mouse model of AD. In the absence of ROS damage, we found a robust oxidative shift in $\mathrm{NAD}(\mathrm{P}) \mathrm{H}$ in non-Tg old age that began earlier in the $3 \times \mathrm{Tg}-\mathrm{AD}$ neurons. The capacity to generate NADH under stress showed substantial deficits in $3 \mathrm{xTg}-\mathrm{AD}$ neurons beginning at 2 months of age. Compared with the non- $\mathrm{Tg}$ neurons from the earliest age (2 months), we also found 3xTg-AD neurons deficient in GSH, which continued throughout the age span. Both $\mathrm{NAD}(\mathrm{P}) \mathrm{H}$ and GSH levels declined in old age in both genotypes. We also observed that in 2-month-old brain extracts, 3xTg-AD neurons had a significantly lower NADH concentration and a more oxidized redox state than the non-Tg neurons. ROS levels were low before 8 months for both genotypes then increased until middle age, but increases were again reversible with nicotinamide. Surprisingly, macromolecular ROS damage was not detected with age or genotype in our in vitro model, unless environmental antioxidants were removed (reduced GSH, vitamin E, vitamin $\mathrm{E}$ acetate, catalase, and SOD). However, in brain extracts, malondialdehyde, hydroxynonenal, and thiobarbituric acid reactive substances levels were elevated in the $3 \mathrm{xTg}-\mathrm{AD}$ relative to non-Tg mouse (Resende et al., 2008). This observation, together with elevated SOD and GSH peroxidase, suggests an insufficient antioxidant response in the $3 \mathrm{xTg}-\mathrm{AD}$ brain in vivo. Interestingly, oxidized GSH was increased and the enzyme to recycle to GSH, GSH reductase, was not increased in the $3 \mathrm{xTg}-\mathrm{AD}$ brain. These observations could be related to our studies because NADPH is a cofactor for GSH reductase in the regeneration of GSH from GSSG. Thus, our measures of lower $\mathrm{NAD}(\mathrm{P}) \mathrm{H}$ in the $3 \mathrm{xTg}-\mathrm{AD}$ neurons would deny sufficient reducing power to the enzyme needed to recycle the GSSG to GSH and to maintain redox balance. If the extracellular antioxidants were removed, $3 x T g-A D$ neurons have significantly higher oxidative damage than non-Tg neurons, as in whole brain.

Several factors could contribute to a decreased $\mathrm{NAD}(\mathrm{P}) \mathrm{H}$ state and an oxidized redox state with age and an $\mathrm{AD}$-like genotype, including the downregulation of TCA cycle enzymes that generate $\mathrm{NADH}$ (Bubber et al., 2005), the lower rates of glycolysis with age (Patel and Brewer, 2003) and $\mathrm{AD}$ (Hoyer et al., 1988, 2005), and the higher energy demands with age and genotype. In addition to glyceraldehyde-3-phosphate dehydrogenase in glycolysis, important sources of NADH are pyruvate dehydrogenase at the entry to the TCA cycle and within the TCA cycle, isocitrate dehydrogenase, $\alpha$-ketoglutarate dehydrogenase, and malate dehydrogenase. Downregulation of any of these enzymes could be responsible for the decreased NADH levels in the 3xTg-AD neuron (Bubber et al., 2005). Yao et al. (2009) observed a significant decline in pyruvate dehydrogenase (PDH) and cytochrome $c$ oxidase (COX) activity in mitochondria isolated from 9- and 12month-old 3xTg-AD brains compared with non-Tg brains. The levels of PDH protein were also significantly lower in $3 \times \mathrm{Tg}-\mathrm{AD}$ brains from the young age of 3 months to the middle age of 12 months, whereas COX levels were significantly lower than in non-Tg brains at 9 and 12 months. In younger embryonic neurons from $3 \mathrm{xTg}-\mathrm{AD}$ mice, maximum respiration stimulated by FCCP was impaired in the $3 \times \mathrm{Tg}$-AD mice compared with the non-Tg mice (Yao et al., 2009). Thus, the availability of NADH for electron transfer is restricted in the $3 \mathrm{xTg}-\mathrm{AD}$ mouse. In neu- 


\section{A NADH concentration}

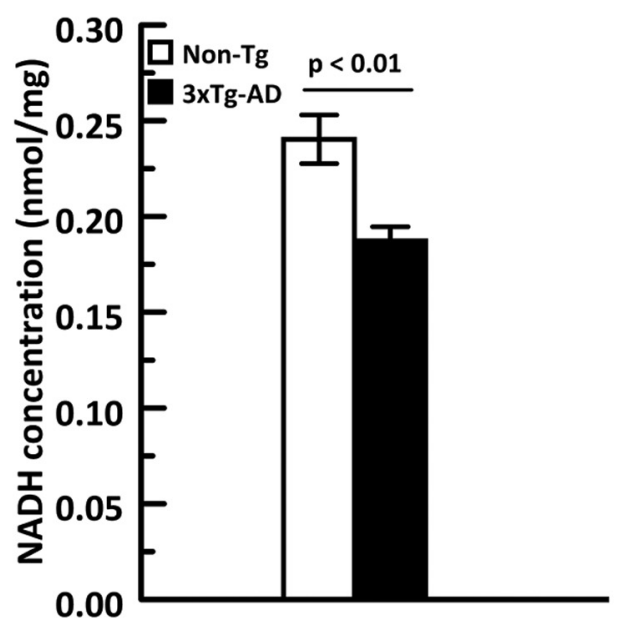

\section{B NADH/NAD redox state}

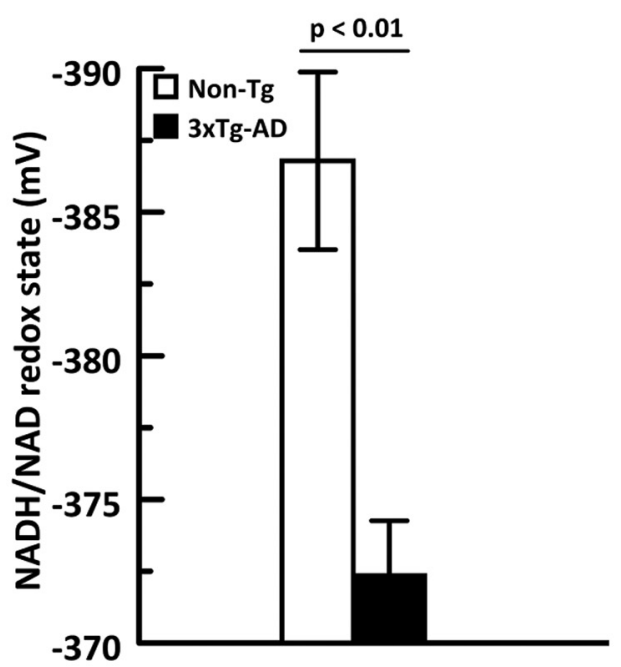

Figure 9. $A, N A D H$ concentration $(\mathrm{nmol} / \mathrm{mg}$ ) by HPLC analysis of frozen forebrain tissue of 2-month-old 3xTg-AD (closed bars) is lower than of non-Tg (open bars) animals. $\boldsymbol{B}$, Calculated NADH/NAD redox state $(\mathrm{mV})$ using the Nernst equation indicates a large oxidative shift in $3 \times \mathrm{Tg}$-AD brain relative to non- $\mathrm{Tg}$ brain. $N=4-6$ mice per genotype.

rons of aged rats, our laboratory has also shown by flux control analysis of the electron transport chain that respiration was limited at the substrate level (NADH) for the NADH-ubiquinone oxidoreductase (Jones and Brewer, 2010). Consequently, a more oxidized environment will contribute to higher rates of ROS generation. This corresponds to our result of decreased $\mathrm{NAD}(\mathrm{P}) \mathrm{H}$ capacity and excessive ROS after middle age.

Nicotinamide, a biosynthetic precursor of $\mathrm{NAD}^{+}$, was previously shown to increase NADH and NADPH levels in striatum and thalamus of whole-brain tissue of adult mouse (Klaidman et al., 2001). Nicotinamide also improved cognitive deficits in hippocampus- and amygdala-dependent tasks in 3xTg-AD mice associated with decreased Thr231 phosphotau, increased levels of the stabilizing form of acetylated $\alpha$-tubulin, and increased synaptogenic p25, with improved learning and memory (Green et al., 2008). In our study, we found that nicotinamide can, in fact, improve earlier agerelated deficits in $\mathrm{NAD}(\mathrm{P}) \mathrm{H}$ concentration, improve the redox ratio to a more normal reduced level, and increase $\mathrm{NADH}$ regenerating capacity.
3xTg-AD mice have an elevated intracellular $\mathrm{Ca}^{2+}$ concentration from birth because of the mutant presenilin (Smith et al., 2005b; Stutzmann et al., 2006), supporting the hypothesis that elevated calcium level contributes to AD (Khachaturian, 1994; Mattson et al., 2000). Calcium can disrupt the mitochondrial membrane potential and increase opening of the mitochondrial transition pore, precipitating cell death. Physiologically elevated calcium also upregulates the NADHgenerating TCA cycle enzyme, $\alpha$-ketoglutarate dehydrogenase (KGDH), in a concentration-related manner (Lai and Cooper, 1986). However, at higher concentrations, calcium inhibits KGDH activity. Thus, age-related elevated calcium level in 3xTg-AD neurons could downregulate KGDH activity with less NADH generation.

Although $\mathrm{NAD}(\mathrm{P}) \mathrm{H}$ acts as redox energy currency, GSH acts as a dynamic redox energy buffer (Das and White, 2002) with millimolar concentrations in rat brain (Kudo et al., 1990; Das and White, 2002) compared with micromolar concentrations of NADH (Gupte et al., 2005). An age-related decrease in GSH is associated with neurodegenerative diseases such as Parkinson's disease and AD (Schulz et al., 2000), which could contribute to increased ROS levels. It is possible that $3 \mathrm{xTg}-\mathrm{AD}$ neurons are unable to generate more GSH because of the decline in $\mathrm{NAD}(\mathrm{P}) \mathrm{H}$ and eventually cannot keep up with higher ROS levels. The reversal of low NAD $(\mathrm{P}) \mathrm{H}, \mathrm{GSH}$, and high ROS levels in 8-month-old $3 \times \mathrm{Tg}-\mathrm{AD}$ neurons by nicotinamide suggests that these redox agents are interlinked.

Cytochrome $c$ is an essential electron carrier in the mitochondrial respiratory chain. We observed that at 2 months, 3xTg-AD neurons already had a significantly higher number of mitochondrial cytochrome $c$ than did non-Tg neurons. Interestingly, though the mitochondrial count per neuron was high in $3 \times T$-AD neurons, the NAD $(\mathrm{P}) \mathrm{H}$ concentration was the same for both non-Tg and 3xTg-AD neurons. The higher mitochondrial count in 3xTg-AD neurons may be needed to compensate for the inefficiency in ATP generation caused by elevated calcium levels (Nicholls, 2009) or amyloid- $\beta$ exposure (Alberdi et al., 2010), either of which would depolarize the mitochondrial membrane potential to lower energy to drive ATP synthesis. However, with age, 3xTg-AD mitochondria have lower $\mathrm{NAD}(\mathrm{P}) \mathrm{H}$ concentrations, suggesting that a depolarized membrane potential drives higher rates of $\mathrm{NADH}$-ubiquinone oxidoreductase that lower $\mathrm{NADH}$ without sufficient regeneration.

Here, we were able to show that an oxidized redox state $(\mathrm{NAD}(\mathrm{P}) \mathrm{H} / \mathrm{FAD})$, lower $\mathrm{NADH}$ regenerating capacity, and lower GSH levels precede excessive ROS in 3xTg-AD compared with non-Tg neurons, a clear effect of redox changes with age on the intrinsic physiology of neurons from the AD model. We also showed that macromolecular damage in neurons was higher in 3xTg-AD neurons when antioxidants were removed from the culture media, but not until 4 months of age. Nicotinamide, which was previously shown to increase NADPH in mouse brain, could also reverse the oxidized redox state to a more reduced state, increase GSH levels, and decrease ROS levels in the neurons. In elegant studies in rats virally transfected with either SOD1 or catalase, age-related learning deficits were also dissociated from accumulated damage (Lee et al., 2011). Because increased ROS levels and macromolecular damage along with decreased GSH levels are hallmarks of $\mathrm{AD}$, any reversal and possible prevention of this damage with nicotinamide may have clinical significance. 


\section{References}

Alberdi E, Sánchez-Gómez MV, Cavaliere F, Pérez-Samartín A, Zugaza JL, Trullas R, Domercq M, Matute C (2010) Amyloid beta oligomers induce $\mathrm{Ca}^{2+}$ dysregulation and neuronal death through activation of ionotropic glutamate receptors. Cell Calcium 47:264-272.

Anderson RM, Weindruch R (2010) Metabolic reprogramming, caloric restriction and aging. Trends Endocrinol Metab 21:134-141.

Brewer GJ (1997) Isolation and culture of adult rat hippocampal neurons. J Neurosci Methods 71:143-155.

Brewer GJ (2010) Epigenetic oxidative redox shift (EORS) theory of aging unifies the free radical and insulin signaling theories. Exp Gerontol 45:173-179.

Brewer GJ, Torricelli JR (2007) Isolation and culture of adult neurons and neurospheres. Nat Protoc 2:1490-1498.

Brewer GJ, Torricelli JR, Evege EK, Price PJ (1993) Optimized survival of hippocampal neurons in B27-supplemented Neurobasal, a new serumfree medium combination. J Neurosci Res 35:567-576.

Brewer GJ, Reichensperger JD, Brinton RD (2006) Prevention of age-related dysregulation of calcium dynamics by estrogen in neurons. Neurobiol Aging 27:306-317.

Brewer GJ, Torricelli JR, Lindsey AL, Kunz EZ, Neuman A, Fisher DR, Joseph JA (2010) Age-related toxicity of amyloid-beta associated with increased pERK and pCREB in primary hippocampal neurons: reversal by blueberry extract. J Nutr Biochem 21:991-998.

Bubber P, Haroutunian V, Fisch G, Blass JP, Gibson GE (2005) Mitochondrial abnormalities in Alzheimer brain: mechanistic implications. Ann Neurol 57:695-703.

Butterfield DA, Koppal T, Howard B, Subramaniam R, Hall N, Hensley K, Yatin S, Allen K, Aksenov M, Aksenova M, Carney J (1998) Structural and functional changes in proteins induced by free radicalmediated oxidative stress and protective action of the antioxidants N-tert-butyl-alpha-phenylnitrone and vitamin E. Ann N Y Acad Sci 854:448-462.

Carney JM, Smith CD, Carney AM, Butterfield DA (1994) Aging- and oxygen-induced modifications in brain biochemistry and behavior. Ann N Y Acad Sci 738:44-53.

Chance B, Williams GR (1956) Respiratory enzymes in oxidative phosphorylation, VI: the effects of adenosine diphosphate on azide-treated mitochondria. J Biol Chem 221:477-489.

Chance B, Schoener B, Oshino R, Itshak F, Nakase Y (1979) Oxidationreduction ratio studies of mitochondria in freeze-trapped samples. $\mathrm{NADH}$ and flavoprotein fluorescence signals. J Biol Chem 254:4764-4771.

Das KC, White CW (2002) Redox systems of the cell: possible links and implications. Proc Natl Acad Sci U S A 99:9617-9618.

Emerit J, Edeas M, Bricaire F (2004) Neurodegenerative diseases and oxidative stress. Biomed Pharmacother 58:39-46.

Eng J, Lynch RM, Balaban RS (1989) Nicotinamide adenine dinucleotide fluorescence spectroscopy and imaging of isolated cardiac myocytes. Biophys J 55:621-630.

Green KN, Steffan JS, Martinez-Coria H, Sun X, Schreiber SS, Thompson LM, LaFerla FM (2008) Nicotinamide restores cognition in Alzheimer's disease transgenic mice via a mechanism involving sirtuin inhibition and selective reduction of Thr231-phosphotau. J Neurosci 28:11500-11510.

Gupte SA, Kaminski PM, Floyd B, Agarwal R, Ali N, Ahmad M, Edwards J, Wolin MS (2005) Cytosolic NADPH may regulate differences in basal Nox oxidase-derived superoxide generation in bovine coronary and pulmonary arteries. Am J Physiol Heart Circ Physiol 288:H13-H21.

Hensley K, Maidt ML, Yu Z, Sang H, Markesbery WR, Floyd RA (1998) Electrochemical analysis of protein nitrotyrosine and dityrosine in the Alzheimer brain indicates region-specific accumulation. J Neurosci 18:8126-8132.

Hoyer A, Bardenheuer HJ, Martin E, Plaschke K (2005) Amyloid precursor protein (APP) and its derivatives change after cellular energy depletion: an in vitro-study. J Neural Transm 112:239-253.

Hoyer S, Oesterreich K, Wagner O (1988) Glucose metabolism as the site of the primary abnormality in early-onset dementia of Alzheimer type? J Neurol 235:143-148.

Hulbert PB, Yakubu SI (1983) Monobromobimane: a substrate for the fluo- rometric assay of glutathione transferase. J Pharm Pharmacol 35: $384-386$.

Jones DP (2006) Redefining oxidative stress. Antioxid Redox Signal 8:1865-1879.

Jones TT, Brewer GJ (2010) Age-related deficiencies in complex I endogenous substrate availability and reserve capacity of complex IV in cortical neuron electron transport. Biochim Biophys Acta 1797: $167-176$.

Kalyanaraman B, Darley-Usmar V, Davies KJ, Dennery PA, Forman HJ, Grisham MB, Mann GE, Moore K, Roberts LJ 2nd, Ischiropoulos H (2012) Measuring reactive oxygen and nitrogen species with fluorescent probes: challenges and limitations. Free Radic Biol Med 52:1-6.

Khachaturian ZS (1994) Calcium hypothesis of Alzheimer's disease and brain aging. Ann N Y Acad Sci 747:1-11.

Klaidman LK, Leung AC, Adams JD Jr (1995) High-performance liquid chromatography analysis of oxidized and reduced pyridine dinucleotides in specific brain regions. Anal Biochem 228:312-317.

Klaidman LK, Mukherjee SK, Adams JD Jr (2001) Oxidative changes in brain pyridine nucleotides and neuroprotection using nicotinamide. Biochim Biophys Acta 1525:136-148.

Kudo H, Kokunai T, Kondoh T, Tamaki N, Matsumoto S (1990) Quantitative analysis of glutathione in rat central nervous system: comparison of GSH in infant brain with that in adult brain. Brain Res 511:326-328.

Lai JC, Cooper AJ (1986) Brain alpha-ketoglutarate dehydrogenase complex: kinetic properties, regional distribution, and effects of inhibitors. J Neurochem 47:1376-1386.

Lee WH, Kumar A, Rani A, Herrera J, Xu J, Someya S, Foster TC (2012) Influence of viral vector-mediated delivery of superoxide dismutase and catalase to the hippocampus on spatial learning and memory during aging. Antioxid Redox Signal 16:339-350.

Lopez JR, Lyckman A, Oddo S, Laferla FM, Querfurth HW, Shtifman A (2008) Increased intraneuronal resting $\left[\mathrm{Ca}^{2+}\right]$ in adult Alzheimer's disease mice. J Neurochem 105:262-271.

Martin B, Ji S, Maudsley S, Mattson MP (2010) “Control” laboratory rodents are metabolically morbid: why it matters. Proc Natl Acad Sci U S A 107:6127-6133

Mattson MP, LaFerla FM, Chan SL, Leissring MA, Shepel PN, Geiger JD (2000) Calcium signaling in the ER: its role in neuronal plasticity and neurodegenerative disorders. Trends Neurosci 23:222-229.

Montine KS, Reich E, Neely MD, Sidell KR, Olson SJ, Markesbery WR, Montine TJ (1998) Distribution of reducible 4-hydroxynonenal adduct immunoreactivity in Alzheimer disease is associated with APOE genotype. J Neuropathol Exp Neurol 57:415-425.

Nicholls DG (2009) Mitochondrial calcium function and dysfunction in the central nervous system. Biochim Biophys Acta 1787:1416-1424.

Nunomura A, Perry G, Pappolla MA, Wade R, Hirai K, Chiba S, Smith MA (1999) RNA oxidation is a prominent feature of vulnerable neurons in Alzheimer's disease. J Neurosci 19:1959-1964.

Oddo S, Caccamo A, Shepherd JD, Murphy MP, Golde TE, Kayed R, Metherate R, Mattson MP, Akbari Y, LaFerla FM (2003a) Triple-transgenic model of Alzheimer's disease with plaques and tangles: intracellular $\mathrm{A} \beta$ and synaptic dysfunction. Neuron 39:409-421.

Oddo S, Caccamo A, Kitazawa M, Tseng BP, LaFerla FM (2003b) Amyloid deposition precedes tangle formation in a triple transgenic model of Alzheimer's disease. Neurobiol Aging 24:1063-1070.

Parihar MS, Brewer GJ (2007) Simultaneous age-related depolarization of mitochondrial membrane potential and increased mitochondrial reactive oxygen species production correlate with age-related glutamate excitotoxicity in rat hippocampal neurons. J Neurosci Res 85:1018-1032.

Parihar MS, Kunz EA, Brewer GJ (2008) Age-related decreases in $\mathrm{NAD}(\mathrm{P}) \mathrm{H}$ and glutathione cause redox declines before ATP loss during glutamate treatment of hippocampal neurons. J Neurosci Res 86:2339-2352.

Patel JR, Brewer GJ (2003) Age-related changes in neuronal glucose uptake in response to glutamate and beta-amyloid. J Neurosci Res 72:527-536.

Reed TT, Pierce WM, Markesbery WR, Butterfield DA (2009) Proteomic identification of HNE-bound proteins in early Alzheimer disease: insights into the role of lipid peroxidation in the progression of $\mathrm{AD}$. Brain Res 1274:66-76.

Resende R, Moreira PI, Proença T, Deshpande A, Busciglio J, Pereira C, 
Oliveira CR (2008) Brain oxidative stress in a triple-transgenic mouse model of Alzheimer disease. Free Radic Biol Med 44:2051-2057.

Safdar A, Hamadeh MJ, Kaczor JJ, Raha S, Debeer J, Tarnopolsky MA (2010) Aberrant mitochondrial homeostasis in the skeletal muscle of sedentary older adults. PLoS One 5:e10778.

Schulz JB, Lindenau J, Seyfried J, Dichgans J (2000) Glutathione, oxidative stress and neurodegeneration. Eur J Biochem 267:4904-4911.

Smith IF, Green KN, LaFerla FM (2005a) Calcium dysregulation in Alzheimer's disease: recent advances gained from genetically modified animals. Cell Calcium 38:427-437.

Smith IF, Hitt B, Green KN, Oddo S, LaFerla FM (2005b) Enhanced caffeine-induced $\mathrm{Ca}^{2+}$ release in the $3 \times \mathrm{Tg}$-AD mouse model of Alzheimer's disease. J Neurochem 94:1711-1718.

Smith MA, Sayre LM, Anderson VE, Harris PL, Beal MF, Kowall N, Perry G
(1998) Cytochemical demonstration of oxidative damage in Alzheimer disease by immunochemical enhancement of the carbonyl reaction with 2,4-dinitrophenylhydrazine. J Histochem Cytochem 46:731-735.

Stutzmann GE, Smith I, Caccamo A, Oddo S, Laferla FM, Parker I (2006) Enhanced ryanodine receptor recruitment contributes to $\mathrm{Ca}^{2+}$ disruptions in young, adult, and aged Alzheimer's disease mice. J Neurosci 26:5180-5189.

Yao J, Irwin RW, Zhao L, Nilsen J, Hamilton RT, Brinton RD (2009) Mitochondrial bioenergetic deficit precedes Alzheimer's pathology in female mouse model of Alzheimer's disease. Proc Natl Acad Sci U S A 106:14670-14675.

Ying W (2008) NAD +/NADH and NADP +/NADPH in cellular functions and cell death: regulation and biological consequences. Antioxid Redox Signal 10:179-206. 